\title{
Seismological imaging of ridge-arc interaction beneath the Eastern Lau Spreading Center from OBS ambient noise tomography
} \author{
William Menke ${ }^{a}$, Robert A. Dunn ${ }^{\mathrm{d}}$, James A. Conder ${ }^{\mathrm{e}}$ \\ a Lamont-Doherty Earth Observatory, Columbia University, Palisades, NY, United States \\ ${ }^{\mathrm{b}}$ Department of Earth and Planetary Sciences, Washington University, St. Louis, MO, United States \\ c Scripps Institution of Oceanography, University of California, San Diego, La Jolla, CA, United States \\ d Department of Geology and Geophysics, University of Hawaii, Honolulu, HI, United States \\ e Department of Geology and Geophysics, Southern Illinois University, Carbondale, IL, United States
}

Yang Zha ${ }^{\mathrm{a}, *}$, Spahr C. Webb ${ }^{\mathrm{a}}$, S. Shawn Wei ${ }^{\mathrm{b}}$, Douglas A. Wiens ${ }^{\mathrm{b}}$, Donna K. Blackman ${ }^{\mathrm{c}}$,

\section{A R T I C L E I N F O}

\section{Article history:}

Received 26 June 2014

Received in revised form 8 October 2014

Accepted 11 October 2014

Available online $\mathrm{xxxx}$

Editor: P. Shearer

\section{Keywords:}

ocean bottom seismograph

ambient noise

Lau Basin

back-arc spreading center

mid-ocean ridge

seismic surface wave

\begin{abstract}
A B S T R A C T
The Lau Basin displays large along-strike variations in ridge characters with the changing proximity of the adjacent subduction zone. The mechanism governing these changes is not well understood but one hypotheses relates them to interaction between the arc and back-arc magmatic systems. We present a 3D seismic velocity model of the shallow mantle beneath the Eastern Lau back-arc Spreading Center (ELSC) and the adjacent Tofua volcanic arc obtained from ambient noise tomography of ocean bottom seismograph data. Our seismic images reveal an asymmetric upper mantle low velocity zone (LVZ) beneath the ELSC. Two major trends are present as the ridge-to-arc distance increases: (1) the LVZ becomes increasingly offset from the ridge to the north, where crust is thinner and the ridge less magmatically active; (2) the LVZ becomes increasingly connected to a sub-arc low velocity zone to the south. The separation of the ridge and arc low velocity zones is spatially coincident with the abrupt transition in crustal composition and ridge morphology. Our results present the first mantle imaging confirmation of a direct connection between crustal properties and uppermost mantle processes at ELSC, and support the prediction that as ELSC migrates away from the arc, a changing mantle wedge flow pattern leads to the separation of the arc and ridge melting regions. Slab-derived water is cutoff from the ridge, resulting in abrupt changes in crustal lava composition and crustal porosity. The larger offset between mantle melt supply and the ridge along the northern ELSC may reduce melt extraction efficiency along the ridge, further decreasing the melt budget and leading to the observed flat and faulted ridge morphology, thinner crust and the lack of an axial melt lens.
\end{abstract}

(C) 2014 Elsevier B.V. All rights reserved.

\section{Introduction}

Spreading rate is often considered the dominant factor controlling melt supply and ridge morphology of mid-ocean ridge systems. Seismological evidence suggests that intermediate- to fast- spreading ridges generally receive higher and more uniform melt supply than slow spreading ridges (see reviews by Spudich and Orcutt, 1980; Dunn and Forsyth, 2007). Back-arc spreading centers are additionally influenced by the changing proximity to the subduction zone and, consequently, to the variable temperature and composition of the mantle wedge. Back-arc spreading centers often have rapid spatial-temporal variations in spreading

\footnotetext{
* Corresponding author.

E-mail address: yangz@ldeo.columbia.edu (Y. Zha).
}

rate (Kato et al., 2003; Zellmer and Taylor, 2001), crustal thickness (Jacobs et al., 2007), geochemical signature (Hawkins et al., 1990; Pearce, 1995; Sinton and Fryer, 1987; Taylor and Martinez, 2003) and ridge morphology (Martinez et al., 2000, 2006). When the spreading center is closer to the volcanic arc, crustal generation may be strongly influenced by subduction-derived fluids, and exhibit enhanced melt production and higher degree of mantle depletion. As spreading progresses, the back-arc basin opens and the ridge gradually shifts away from the volcanic arc, reducing the influence of subduction until the spreading center becomes similar to a mid-ocean ridge.

The Eastern Lau Spreading Center (ELSC) in the Lau back-arc basin is characterized by rapid along-strike variations of many variables, presenting an excellent opportunity for studying the interaction between subduction and ridge processes. From south to north, the spreading rate of the ELSC increases from $\sim 40 \mathrm{~mm} / \mathrm{yr}$ 
to $\sim 95 \mathrm{~mm} / \mathrm{yr}$ and the distance from the ridge to the volcanic arc increases from about $40 \mathrm{~km}$ to $100 \mathrm{~km}$ (Zellmer and Taylor, 2001). Crustal thickness decreases from 8-9 km at the central ELSC and Valu Fa Ridge (VFR) to 6-7 km at the northern ELSC (Arai and Dunn, 2014; Crawford et al., 2003; Jacobs et al., 2007; Turner et al., 1999). Crustal composition changes from andesitic with a strong arc signature to tholeiitic, similar to mid-ocean ridge basalts (Escrig et al., 2009; Pearce et al., 1994; Pearce, 1995; Peate et al., 2001). Despite the spreading rate increasing northward, the northern ELSC appears to have reduced magmatic activity. The seismically imaged axial melt lens goes from continuous at the south to discontinuous or absent in the north (Jacobs et al., 2007). Additionally, the axial depth of the ridge increases from $1700 \mathrm{~m}$ to over $2700 \mathrm{~m}$ and the ridge axis morphology changes from an inflated axial rise to a faulted axial valley (Martinez et al., 2006). This opposing trend of ridge characteristics with spreading rate compared to mid-ocean ridges suggests that crustal production at the ELSC is dominated by varying mantle wedge properties rather than spreading rate (Martinez et al., 2006).

Despite the well documented trend of surface ridge characteristics at the ELSC, few seismic studies have imaged the 3D velocity variation in the mantle wedge, and the interaction between wet melting beneath the arc and decompression melting beneath the back-arc remains poorly understood. Previous seismic studies have mainly focused on the Central Lau Spreading Center (CLSC) to the north of the ELSC, where the ridge is further from the volcanic arc (distance $>170 \mathrm{~km}$ ) and the spreading is similar to a typical mid-ocean ridge. Some previous body wave tomography studies imaged separate upper mantle low velocity zones beneath the spreading center and the arc (Zhao et al., 1997), whereas others show a continuous low velocity region centered under the CLSC (Conder and Wiens, 2006), leaving the spatial configuration of the mantle magma sources unclear. A recent high-resolution active-source tomographic study revealed an abrupt change in upper crustal seismic velocities along and across the ELSC near $20^{\circ} 30^{\prime} \mathrm{S}$, indicative of a sudden change in the mantle source entrained by the ridge (Dunn and Martinez, 2011; Dunn et al., 2013). This abrupt change is in spatial coincidence with the sharp change in lava composition sampled along the ELSC (Escrig et al., 2009). A 3D seismic imaging study of the upper mantle was conducted to better understand the cause of this abrupt change and the interaction of arc and back-arc magmatic systems.

Cross-correlation of ambient seismic noise records can be used to infer the impulse responses (or empirical Green's functions) between pairs of seismic stations, which can then be analyzed for the 3D earth structure (Shapiro and Campillo, 2004; Snieder, 2004). This method has been widely applied to study seismic structures from regional to continental scales (Lin et al., 2008; Shapiro et al., 2005). However, few studies to date have applied ambient noise tomography to ocean bottom seismograph (OBS) data (Harmon et al., 2007; Takeo et al., 2013; Yao et al., 2011). In this paper, we present a 3D shear velocity model of the shallow mantle beneath the ELSC, derived from ambient noise tomography of OBS data from the 2009-2010 ELSC Seismic Experiment. By using both vertical and horizontal components of OBS data, we retrieved phase velocity dispersion of Rayleigh and Love waves and inverted them for the shear velocity structure of the upper $50 \mathrm{~km}$. Our model delineates shear velocity variation along the ELSC, including low velocity regions beneath both the arc volcanoes and the spreading center. Our results shed light on the origin of the rapid along-strike changes of ridge characteristics at the ELSC, and provide new insights into the interaction between arc and back-arc magmatic systems in an active back-arc basin.

\section{Geological settings}

The Eastern Lau Spreading Center is located in the southeastern Lau basin, a wedge-shaped back-arc basin between the subducting Pacific Plate and the overriding Australian Plate. The Lau basin is bounded by the active Tofua Arc and the remnant Tonga Ridge to the east and the remnant Lau Ridge to the west. Opening of the Lau basin began at $6 \mathrm{Ma}$, starting as rifting in the northern section of the basin and subsequently evolving into seafloor spreading, splitting the original Tonga arc crust into the remnant Tonga Ridge and Lau Ridge (Karig, 1970; Taylor et al., 1996). The spreading propagated southward, giving the basin its triangular shape.

The current phase of spreading in the Lau basin occurs along several north-south striking segments from $24^{\circ} \mathrm{S}$ to $15^{\circ} \mathrm{S}$ (Conder and Wiens, 2006; Zellmer and Taylor, 2001). From south to north, the spreading rate increases from $30 \mathrm{~mm} / \mathrm{yr}$ at the southern Valu Fa ridge (VFR) to $95 \mathrm{~mm} / \mathrm{yr}$ at the northern end of the ELSC (Martinez et al., 2006; Zellmer and Taylor, 2001). The ELSC consists of four individual segments separated by overlapping spreading centers (Dunn et al., 2013; Martinez et al., 2006; Taylor et al., 1996). Spreading along the ELSC terminates at its northern end near $19^{\circ} 20^{\prime} \mathrm{S}$, jumping westward to the Central Lau Spreading Center (CLSC) with an offset greater than $50 \mathrm{~km}$. The CLSC is spreading at a relatively constant rate of $8.5 \mathrm{~cm} / \mathrm{yr}$ along its $110 \mathrm{~km}$ stretch (Zellmer and Taylor, 2001). Further north, the CLSC transitions into an extensional transform zone and the Peggy Ridge (PR). In the Northern Lau Basin, extension becomes more diffuse, and the spreading may be accommodated by relative motion between several micro-plates (Pelletier et al., 2001; Zellmer and Taylor, 2001).

The ELSC/VFR spreading system can be divided into three sections based on axial morphology (Martinez et al., 2006): Valu Fa Ridge (VFR, $22^{\circ} 45^{\prime}-21^{\circ} 26^{\prime} \mathrm{S}$ ), Central ELSC (c-ELSC, $21^{\circ} 26^{\prime}-$ $20^{\circ} 32^{\prime} \mathrm{S}$ ) and Northern ELSC (n-ELSC, $20^{\circ} 32^{\prime}-19^{\circ} 20^{\prime} \mathrm{S}$ ). With increasing distance to the volcanic arc northward, the ELSC/VFR system shows decreasing subduction influence. Along the VFR and c-ELSC, the sampled lavas are highly vesicular and have an arc-like composition, characterized by low $\mathrm{Mg}$ number and a higher degree of depletion (Escrig et al., 2009; Pearce et al., 1994; Taylor and Martinez, 2003; Vallier et al., 1991). The crust along the VFR and c-ELSC is 8-9 km thick (Turner et al., 1999), and there exists a thick upper crustal region of low velocities (Jacobs et al., 2007). The ridge axis is marked by either a sharp (VFR) or rounded (c-ELSC) axial high (Jacobs et al., 2007; Martinez et al., 2006). A continuous axial melt lens has been imaged at $2-3 \mathrm{~km}$ below the seafloor (Jacobs et al., 2007).

North of $20^{\circ} 30^{\prime} \mathrm{S}$, the crust transitions from arc-like to MORBlike along the n-ELSC (Escrig et al., 2009; Pearce et al., 1994; Pearce, 1995). The ridge morphology changes from axial high to axial valley (Jacobs et al., 2007; Martinez et al., 2006; Sleeper and Martinez, 2014). The axial melt lens becomes absent, and the crustal thickness decreases to $6-7 \mathrm{~km}$, indicating a reduced melt supply to the ridge. The upper crustal velocity increases abruptly by as much as $1 \mathrm{~km} / \mathrm{s}$ (Arai and Dunn, 2014; Dunn and Martinez, 2011), consistent with basaltic compositions and reduced upper crustal porosity, associated with less volatiles in the magma.

Further north at the CLSC, both the crustal thickness $(6-7 \mathrm{~km})$ and lava composition are similar to that of fast-spreading midocean ridges (Jacobs et al., 2007; Pearce, 1995; Taylor and Martinez, 2003). The axial melt lens is present and sits at a depth of 1-2 km, similar to the fast-spreading East Pacific Rise (EPR). These observations suggest that subduction influence may be negligible along the CLSC. 

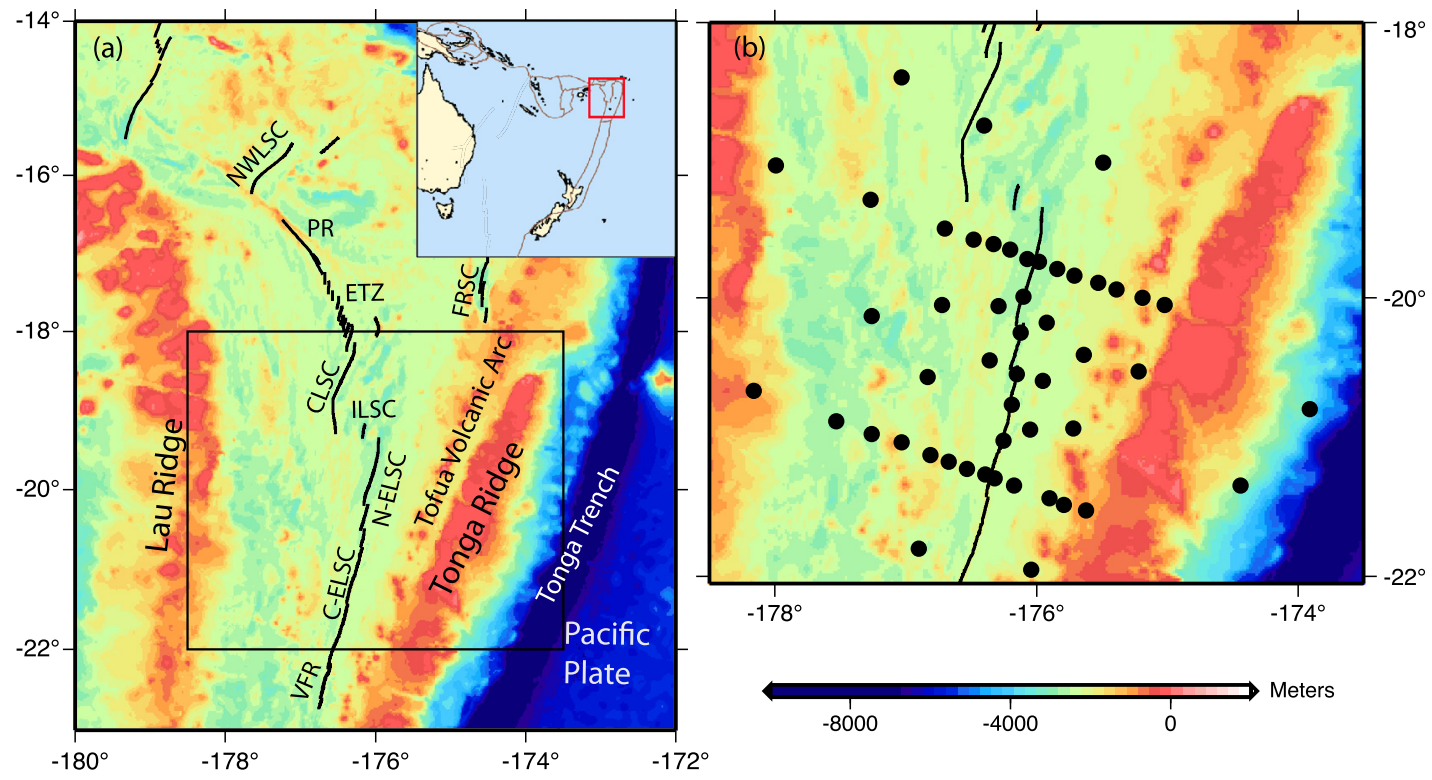

(c)

(d)

T-T
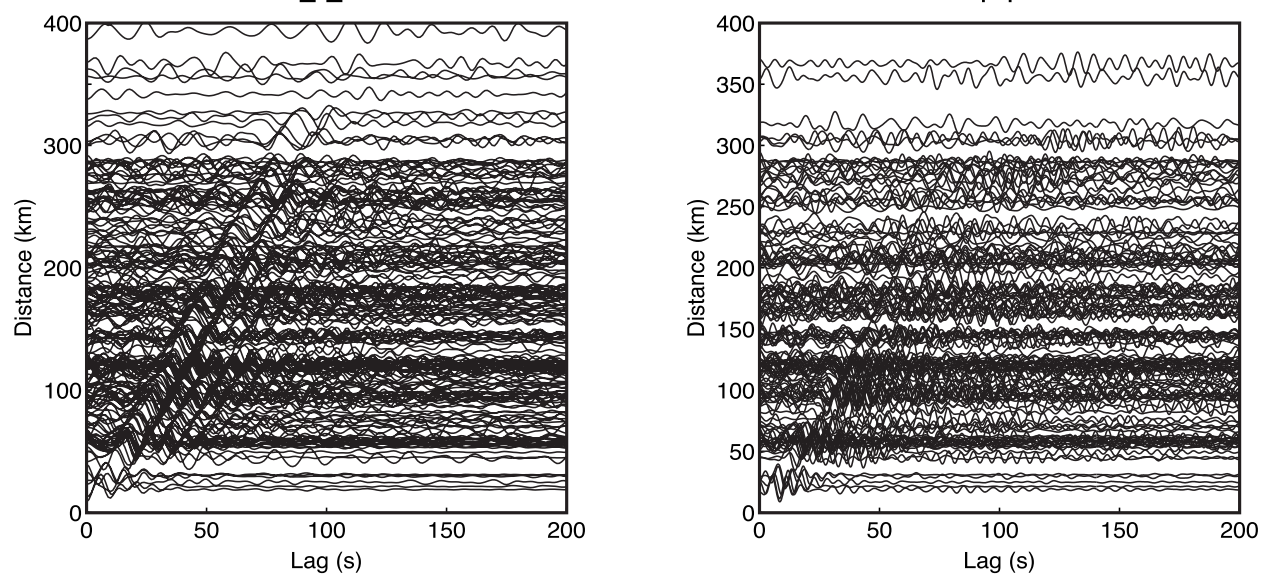

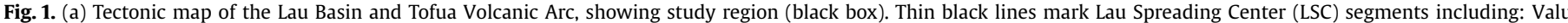

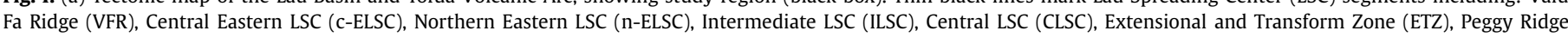

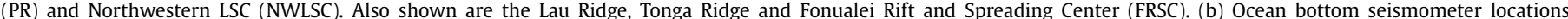

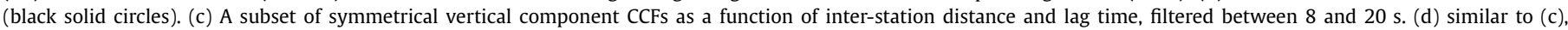
but for transverse component CCFs filtered between 5 and $15 \mathrm{~s}$.

\section{Data and methods}

The data analyzed in this paper were collected during the Eastern Lau Spreading Center Seismic Experiment, which included deployments of 51 broadband OBSs from November 2009 to December 2010 (Fig. 1), each equipped with a 3-component broadband seismometer and a pressure sensor. Usable data was recovered from 50 of the OBSs. The array consisted of two lines perpendicular to the ridge, as well as a dense network of stations between the two lines and some stations in the CLSC and VFR areas. The 3D array provides dense coverage of the ELSC segment of the Lau basin from Lau Ridge to the Tonga Ridge, with the best coverage along the transitional part of the ELSC.

Cross-correlation of ambient seismic noise records can be used to extract the impulse responses between pairs of stations that can be analyzed to obtain surface wave dispersion information between station pairs (Shapiro and Campillo, 2004; Snieder, 2004). The ambient noise correlation can be performed in either time or frequency domain (Bensen et al., 2007; Ekström et al., 2009). In this paper we use a frequency-domain method (Aki, 1957; Ekström et al., 2009) to estimate the phase velocities of Rayleigh and Love waves propagating between each OBS pair. The pathaveraged phase velocity measurements are then inverted for phase velocity maps as a function of frequency. The phase velocity maps are inverted for a 3D shear velocity model.

\subsection{Spectral noise cross-correlation}

The raw 3-component OBS data are first quality-controlled and corrected for clock drift and instrument responses. We determined the horizontal orientation of each OBS using the noise-based method by Zha et al. (2013). Data were rotated into a verticaleast-north coordinate system. The daily seismograms were decimated to $5 \mathrm{~Hz}$ sampling rate and cut into 100 overlapping windows. Each short seismogram window was tapered and Fourier transformed to the frequency domain. A cross-correlation spectra $\rho_{i j}(\omega)$ between each OBS pair $i-j$ was calculated from the Fourier transforms $p_{i}$ and $p_{j}$ for each window and normalized by the spectral amplitudes:

$$
\rho_{i j}=\frac{p_{i}(\omega) p_{j}^{*}(\omega)}{\left|p_{i}(\omega)\right|\left|p_{j}(\omega)\right|}
$$


This result was averaged over all windows in a day and stacked over all days to form the ensemble averaged crosscorrelation spectra $\overline{\rho_{i j}(\omega)}$ (which is closely related to coherence). The frequency-domain normalization for each short time window effectively prevents waves from large earthquakes from dominating the signal, while not modifying the data as aggressively compared to the commonly used time domain one-bit normalization (Bensen et al., 2007; Calkins et al., 2011). For Rayleigh wave dispersion analysis, spectra of two vertical component data records were used. For Love waves, horizontal component spectra were first rotated into radial-transverse coordinates, and the transverse component used to calculate the cross-correlation spectra. A subset of stacked time domain cross-correlation functions (CCFs) are shown in Fig. 1. Coherent moveouts associated with fundamental mode Rayleigh and Love waves are clearly visible from the vertical and transverse CCFs, respectively. Coherent signals related to higher mode Rayleigh waves and body waves have been reported previously by other studies (Harmon et al., 2007; Roux, 2005). However no higher modes or body wave signals of sufficient energy are observed in the time domain CCFs, so we limit our analysis to the fundamental modes.

\subsection{Extracting phase velocity dispersion}

We measured the phase velocity dispersion of fundamental mode Rayleigh and Love waves using a spectral formulation based on Aki (1957) and Ekström et al. (2009), which uses the zerocrossings of $\overline{\rho(\omega)}$ to calculate phase velocities at those frequencies. Compared to time-domain methods, this approach allows extracting phase velocity dispersion from station pairs at shorter distances (Ekström et al., 2009). An example of the calculation of phase velocity dispersion curves is shown in Fig. S1.

This approach generates phase velocity values for a suite of possible dispersion curves, due to extra and missing zeros in $\overline{\rho(\omega)}$ caused by un-correlated noise. We adopted a previous velocity model from the eastern Lau Basin by Crawford et al. (2003) and a $V_{P} / V_{S}$ ratio of 1.85 (Conder and Wiens, 2006) to generate a reference dispersion curve. Then the dispersion curve closest to the reference curve at the longest period is chosen. Phase velocities at shorter period are subsequently selected using an automated algorithm, which searches for the smoothest dispersion curve that also yields reasonable group velocity values. The resulting dispersion curves are interpolated onto a uniform range of wave periods from 2 to $20 \mathrm{~s}$, at uniform $0.5 \mathrm{~s}$ interval.

We obtain phase velocity dispersion curves along 1225 interstation paths between the 50 OBS stations. For each frequency, only station pairs with distances longer than twice the wavelength are included, and dispersion curves with physically unacceptable velocity values and step-like jumps are discarded. Additionally, short period ( $<20 \mathrm{~s}$ ) Rayleigh wave phase velocities are greatly affected by ocean depth. Waves that propagate between shallow and deep sites are subject to ray-bending and scattering effects due to large phase velocity changes. To prevent these effects from contaminating the phase velocity measurements, we also discard dispersion curves between stations that have depth differences of $1000 \mathrm{~m}$ or more. The criteria of $1000 \mathrm{~m}$ is selected empirically after inspecting cross-correlation spectra between station pairs of various depth differences. After data selection, the number of dispersion curves used for inversion ranges from 752 at $8 \mathrm{~s}$ to 174 at $18 \mathrm{~s}$ for Rayleigh waves, and 177 at $6 \mathrm{~s}$ to 95 at $9 \mathrm{~s}$ for Love waves. The narrow band and small number of Love wave measurements is the result of high levels of un-correlated noise on the horizontal components, probably due to high tilt noise associated with ocean bottom current (Crawford and Webb, 2000).

\subsection{Phase velocity map inversion}

We invert the selected dispersion curves for phase velocity maps from 8 to $18 \mathrm{~s}$ for Rayleigh waves and from 6 to $9 \mathrm{~s}$ for Love waves. The tomographic inversion was performed using a generalized least-square algorithm (Barmin et al., 2001; Menke, 2012) on a uniform grid of $0.1^{\circ} \times 0.1^{\circ}$ rectangular cells. For each period, we use a homogeneous and isotropic starting model with the average phase velocity from all dispersion curves. We use a finite-frequency influence zone approximation to construct sensitivity kernels (Yoshizawa and Kennett, 2002). This approximation is computationally straightforward, while still taking into account the finite frequency effects. A small amount of roughness damping and perturbation-amplitude damping are applied to ensure model smoothness and reduce spurious anomalies in regions with low ray coverage, following Barmin et al. (2001). Spatially variable weak azimuthal anisotropy with a $2 \theta$ velocity variation (Smith and Dahlen, 1973) for Rayleigh waves is included in the inversion.

We present here only the isotropic part of Rayleigh wave phase velocity. The anisotropic results will be presented separately with the shear wave splitting analysis of anisotropy (Menke et al., 2014). Due to fewer ray paths and poorer azimuthal coverage, Love wave velocities are assumed to be isotropic. The uncertainties of the phase velocity maps are estimated using a bootstrap algorithm (Calkins et al., 2011; Menke and Menke, 2012) (see Appendix A, Fig. S2 and Fig. S3) and subsequently used in the shear velocity inversion.

\subsection{Shear velocity inversion}

At each spatial point of the grid, we jointly invert Rayleigh and Love isotropic phase velocity values for depth-varying isotropic velocity structure to $50 \mathrm{~km}$ depth, using an iterative linearized inversion code (Herrmann, 2004). The velocity model is parameterized with constant velocity layers of varying thicknesses. The thickness of the water layer corresponds to the average ocean depth within that grid cell. Below the seafloor, layer thickness is $1 \mathrm{~km}$ in the top $15 \mathrm{~km}$ and $5 \mathrm{~km}$ below. Crustal thickness in the Lau basin is highly variable, from $6 \mathrm{~km}$ at CLSC and 8-9 km at VFR to over $15 \mathrm{~km}$ at the Tonga Ridge (Crawford et al., 2003; Turner et al., 1999). Prior information on crustal thickness could potentially improve constraints on crustal velocity. However, although crustal structure has been studied in detail in some regions (Arai and Dunn, 2014; Crawford et al., 2003; Dunn et al., 2013; Jacobs et al., 2007; Turner et al., 1999), crustal thickness information at ELSC is very limited outside a small area studied by Arai and Dunn (2014). Extrapolating crustal thickness outside of their study area is also difficult due to ridge propagation and rapidly varying crustal structure both along and perpendicular to the ELSC (Arai and Dunn, 2014; Dunn and Martinez, 2011). Therefore we do not assume any prior crustal thickness and instead apply a conservative two-step inversion process. We first invert the average Rayleigh- and Love-wave dispersion curves, starting with a half-space model, to obtain a smooth average model (Fig. S4). We then invert for 1D structure at each grid point to construct the 3D model, using the smooth model as a starting model. We discuss the possible trade-off between crustal thickness and velocity in Section 4.2. To stabilize the inversion of deeper structure, we only include Rayleigh wave phase velocities in the first 10 iterations, and add in Love wave phase velocities in the next 10 iterations to refine the shallow structure. A resolution analysis is presented in Appendix A.

Weak radial anisotropy has been shown to exist in young oceanic lithosphere (Nishimura and Forsyth, 1989). Using both Rayleigh and Love wave phase velocity values one could potentially calculate radial anisotropy. However, the Rayleigh and Love 

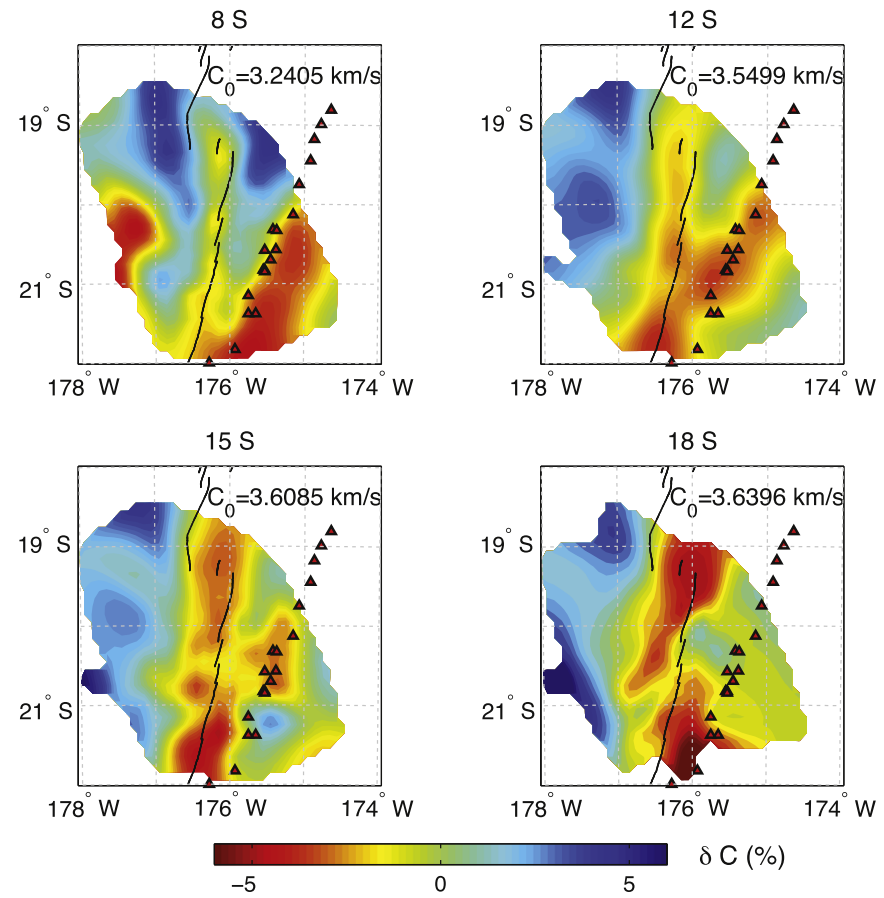

Fig. 2. Rayleigh wave phase velocity anomalies (in \%) at period of 8, 12, 15 and $18 \mathrm{~s}$. The average phase velocity of each period is shown on map. Only regions with ray coverage are shown. The spreading centers (black curves) and arc volcanoes (red triangles) are also shown. (For interpretation of the references to color in this figure legend, the reader is referred to the web version of this article.)

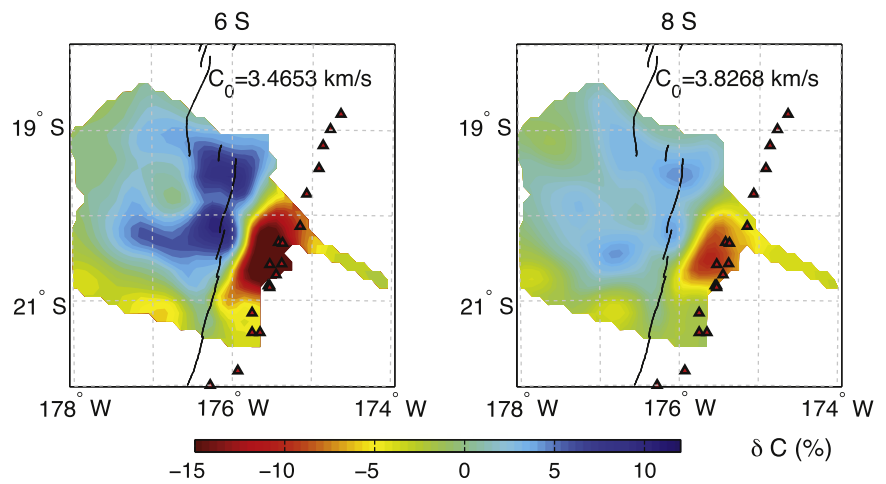

Fig. 3. Love wave phase velocity anomalies (in \%) at periods of 6 and $8 \mathrm{~s}$. The average phase velocity of each period is shown on map. The spreading center (black curves) and arc volcanoes (red triangles) are also shown. (For interpretation of the references to color in this figure legend, the reader is referred to the web version of this article.)

wave phase velocity values used in this study fall into different frequency bands, and their sensitivity kernels have little overlap in depth (Fig. S4). Thus they provide independent constraints on velocities at different depths, but little constraint on radial anisotropy. We therefore chose to not compute radial anisotropy as part of the solution.

\section{Results}

\subsection{Phase velocity maps}

Estimated Rayleigh- and Love-wave phase velocity maps are shown in Fig. 2 and Fig. 3, respectively. Compared to the starting homogeneous Rayleigh wave phase velocity maps, inverted phase velocity maps show significant misfit reductions. Normalized misfit $\chi^{2}$ decreased from values from 6 to 385 (varying

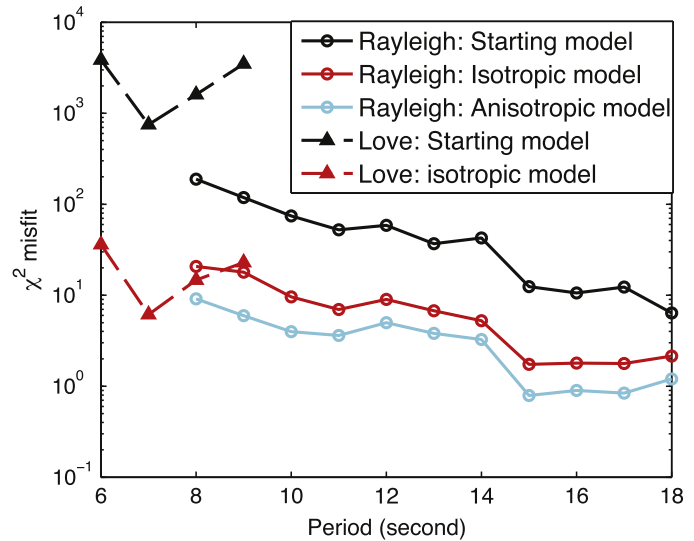

Fig. 4. Normalized misfit $\chi^{2}$ as a function of period, plotted in log scale, for Rayleigh waves (solid curve with circles) and Love waves (dashed curve with triangles), before and after tomographic inversion. Note that the misfit is reduced at all periods, both between the starting model and isotropic model and between the isotropic model and anisotropic model.

with period) for the starting model to $0.8-9$ for the final model (Fig. 4). Variance reductions (defined as $1-\chi_{\text {final }}^{2} / \chi_{\text {start }}^{2}$ ) of inverted Rayleigh wave phase velocity maps are systematically higher for azimuthally anisotropic models (81\% to $95 \%$ ) than isotropic models (66\% to $89 \%)$, suggesting that azimuthal anisotropy is required to fit phase dispersion measurements. The average peakto-peak amplitudes of azimuthal anisotropy range from $2.8 \%$ to $4.6 \%$, with fast directions generally sub-parallel to the spreading axis (Fig. S5). More complete anisotropy results are presented in detail separately in Menke et al. (2014), and the analysis in this paper will focus on the azimuthally averaged phase velocity maps.

Rayleigh wave phase velocity maps at $8,12,15$ and 18 seconds are shown in Fig. 2. At the shortest periods ( $8 \mathrm{~s}$ ), the slowest velocities (about $-5 \%$ ) occur beneath the relict Tonga Ridge, and are associated with the thick, highly porous volcanic arc crust. At longer periods (12-15 s), the slow phase velocity zone shift westwards to beneath the active Tofua Arc. The ELSC is underlain by a continuous zone of moderately slow anomaly (about $-1 \%$ to $-3 \%$ ). Fast anomalies up to $+6 \%$ are imaged west of the ELSC and in the region between the ELSC and Tonga Ridge. At long period (18 s), the slow anomaly beneath the Tonga Ridge becomes weaker and less continuous, while the slow anomaly beneath the ELSC increases in both width and amplitude. The region west of the ELSC between $21^{\circ} \mathrm{S}$ and $19^{\circ} 30^{\prime} \mathrm{S}$ exhibits a slow velocity anomaly at $8 \mathrm{~s}$, but a fast anomaly for periods $12 \mathrm{~s}$ and greater. A comparison with local bathymetry suggests that this is likely an effect of seafloor topography rather than subsurface geology, because short-period Rayleigh wave phase velocities are highly sensitive to bathymetry. In order to separate bathymetric effects from sub-seafloor heterogeneity, the geographically-varying thickness of the water layer must be taken into account.

Love wave phase velocity maps at 6 and 8 s show different patterns from the Rayleigh wave maps (Fig. 3). While the Tonga Arc region is still characterized by slow anomalies, a prominent fast anomaly (up to $+10 \%$ ) is imaged at the northern ELSC near the spreading center. Because short period Love waves from 5-9 s are mainly sensitive to the velocity structure of the upper $10 \mathrm{~km}$ (Fig. S4), this fast anomaly is likely associated with the crustal velocity variations at ELSC. The amplitude of the fast anomaly is higher at $6 \mathrm{~s}$ than $8 \mathrm{~s}$, indicating that the source of the fast anomaly may be shallow. 

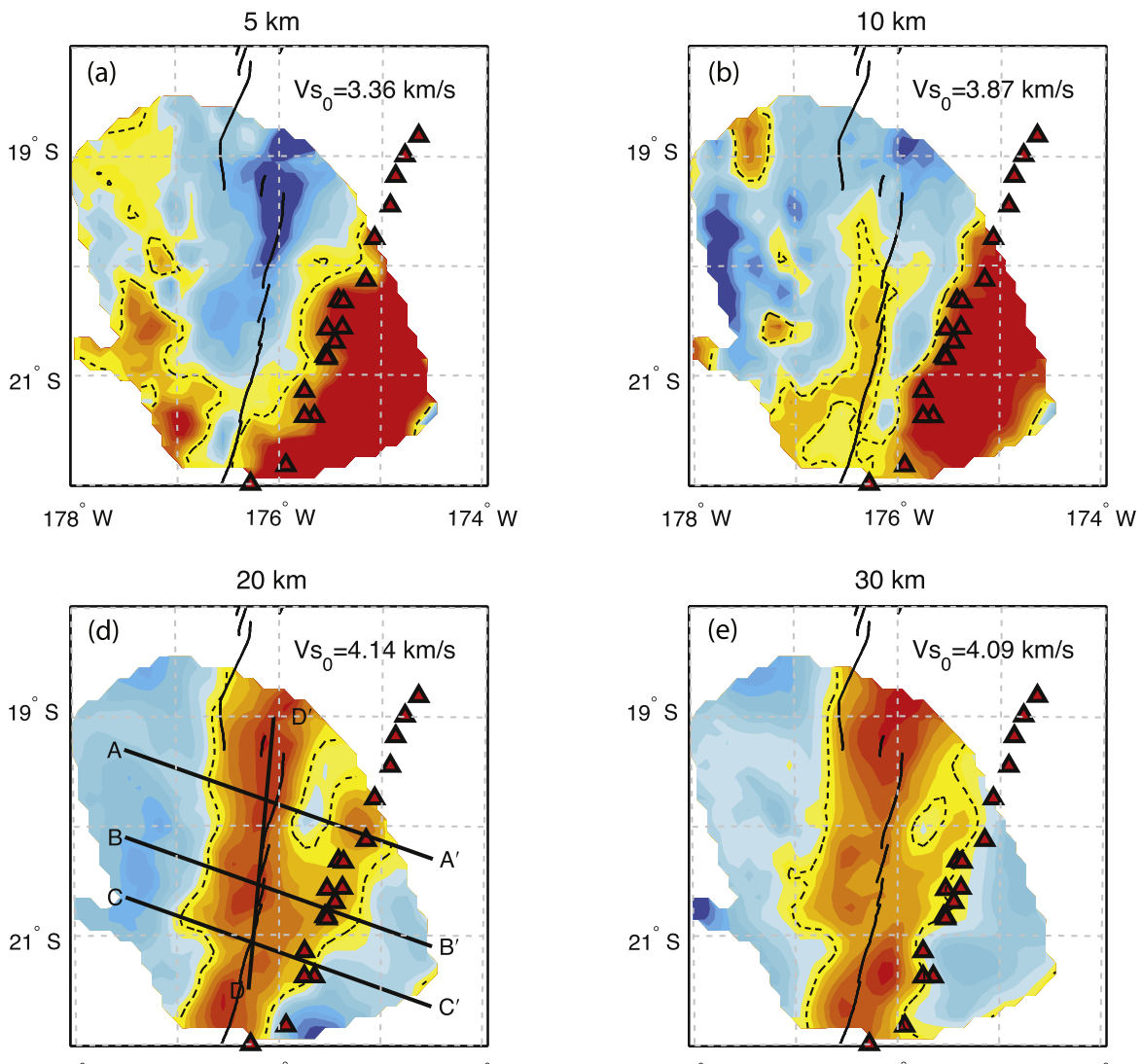

$178^{\circ} \mathrm{W}$ $176^{\circ} \mathrm{W}$

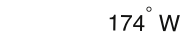

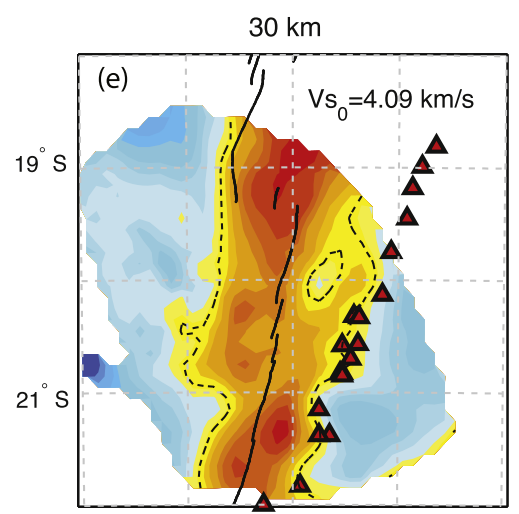

$178^{\circ} \mathrm{W}$

$176^{\circ} \mathrm{W}$ $174^{\circ} \mathrm{W}$
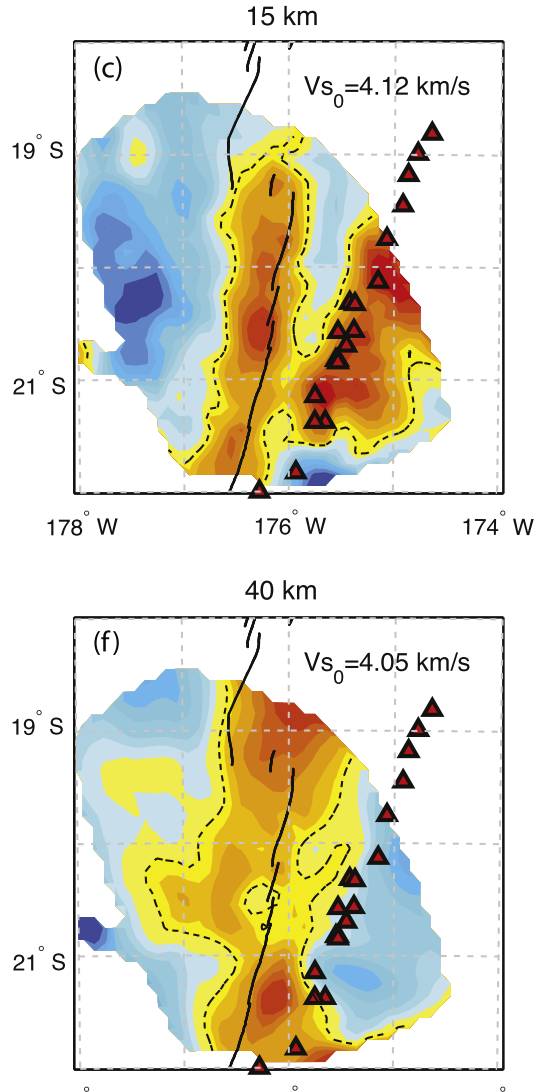

$178^{\circ} \mathrm{W}$ $174^{\circ} \mathrm{W}$

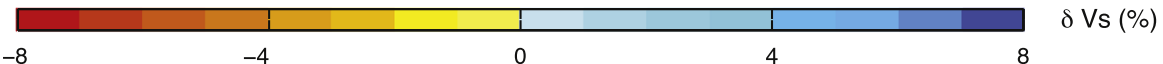

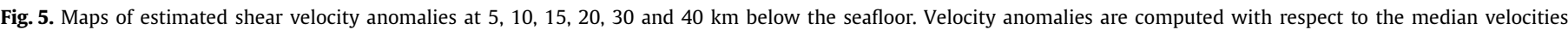

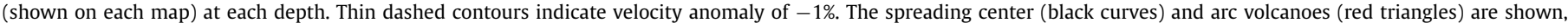

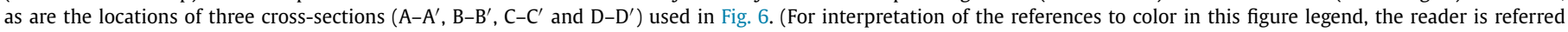
to the web version of this article.)

\subsection{Shear velocity structure}

We inverted the network average Rayleigh and Love phase velocities for a 1D average velocity model (Fig. S4b). Shear velocity $V_{S}$ in the $1 \mathrm{D}$ model increases from about $3 \mathrm{~km} / \mathrm{s}$ near the seafloor to about $4.1 \mathrm{~km} / \mathrm{s}$ at about $20 \mathrm{~km}$ depth, then decreases in the upper mantle to a minimum of about $4 \mathrm{~km} / \mathrm{s}$ at about $40 \mathrm{~km}$ depth. A previous Lau Basin model (Wiens et al., 2006) and a 0-4 myr Pacific plate model (Nishimura and Forsyth, 1989) have similar mantle velocities in the $20-40 \mathrm{~km}$ depth range, but differ substantially at shallower depths, probably due to limited resolution of long period surface waves at shallow depths in the previous studies.

\subsubsection{Lateral variation of crustal structure}

Horizontal and vertical slices of the 3D shear velocity model are shown in Fig. 5 and Fig. 6. Significant velocity variation is imaged both across and along the ELSC. Because we assume a smooth model in the inversion, the recovered model does not have an explicit Moho discontinuity. We instead use $V_{s}=3.8 \mathrm{~km} / \mathrm{s}$ to serve as a proxy for the bottom of the crust (Fig. 6). We note that this proxy is not valid beneath the ridge due to the mantle low velocity anomaly. At $5 \mathrm{~km}$ depth crustal velocities exhibit a striking correlation with documented seafloor geology (Fig. 5a). Large slow anomalies (up to $-20 \%$ ) are imaged beneath the Tonga Ridge, corresponding to the porous volcanic arc crust. This arc crust signature extends to $15-20 \mathrm{~km}$ depth (Fig. 6), in agreement with previous results showing that the crust is more than $15 \mathrm{~km}$ thick just north of $19^{\circ} \mathrm{S}$ (Crawford et al., 2003), and with older data suggesting crustal thicknesses of 20-25 km (Mitronovas and Isacks, 1971; Raitt et al., 1955). To the southwest of the ELSC, two shallowrooted low velocity anomalies are imaged beneath two isolated seamounts. Velocities are higher in the central part of the Lau basin near the ELSC, consistent with seismically faster gabbroic oceanic crust. A wedge-shaped high velocity zone (anomaly $>10 \%$ ) is imaged beneath the n-ELSC, consistent with the results for upper crustal compressional velocity from active source seismic tomography (Dunn et al., 2013). This high velocity zone also covers the Intermediate Lau Spreading Center (ILSC), but does not extend to the CLSC. The shape of this zone and sharp velocity increase from the c-ELSC to the n-ELSC correlates spatially with an abrupt change in seafloor depth and seafloor morphology (Martinez et al., 2006). The crust at n-ELSC was shown to be $\sim 2 \mathrm{~km}$ thinner than that at c-ELSC (Arai and Dunn, 2014; Crawford et al., 2003; Turner et al., 1999). Since no prior information on crustal thickness is included in the inversion, the high crustal velocity could be partly caused by a thinner crust at the n-ELSC, because a larger portion of the mantle is sampled at the n-ELSC than the c-ELSC.

To test if the high velocity zone is purely an artifact from a thinner crust, we select two locations at n-ELSC and c-ELSC, and perform another set of $1 \mathrm{D}$ inversions at each location using predefined crustal thicknesses (Fig. S6). The starting model at each location is the final model from previous 3D inversion, with the crustal portion substituted by a constant velocity layer $\left(V_{s}=3.5 \mathrm{~km} / \mathrm{s}\right)$. The crust is set to be $5.5 \mathrm{~km}$ thick at n-ELSC (the lower bound in Crawford et al., 2003) and $9 \mathrm{~km}$ thick at c-ELSC (the upper bound 

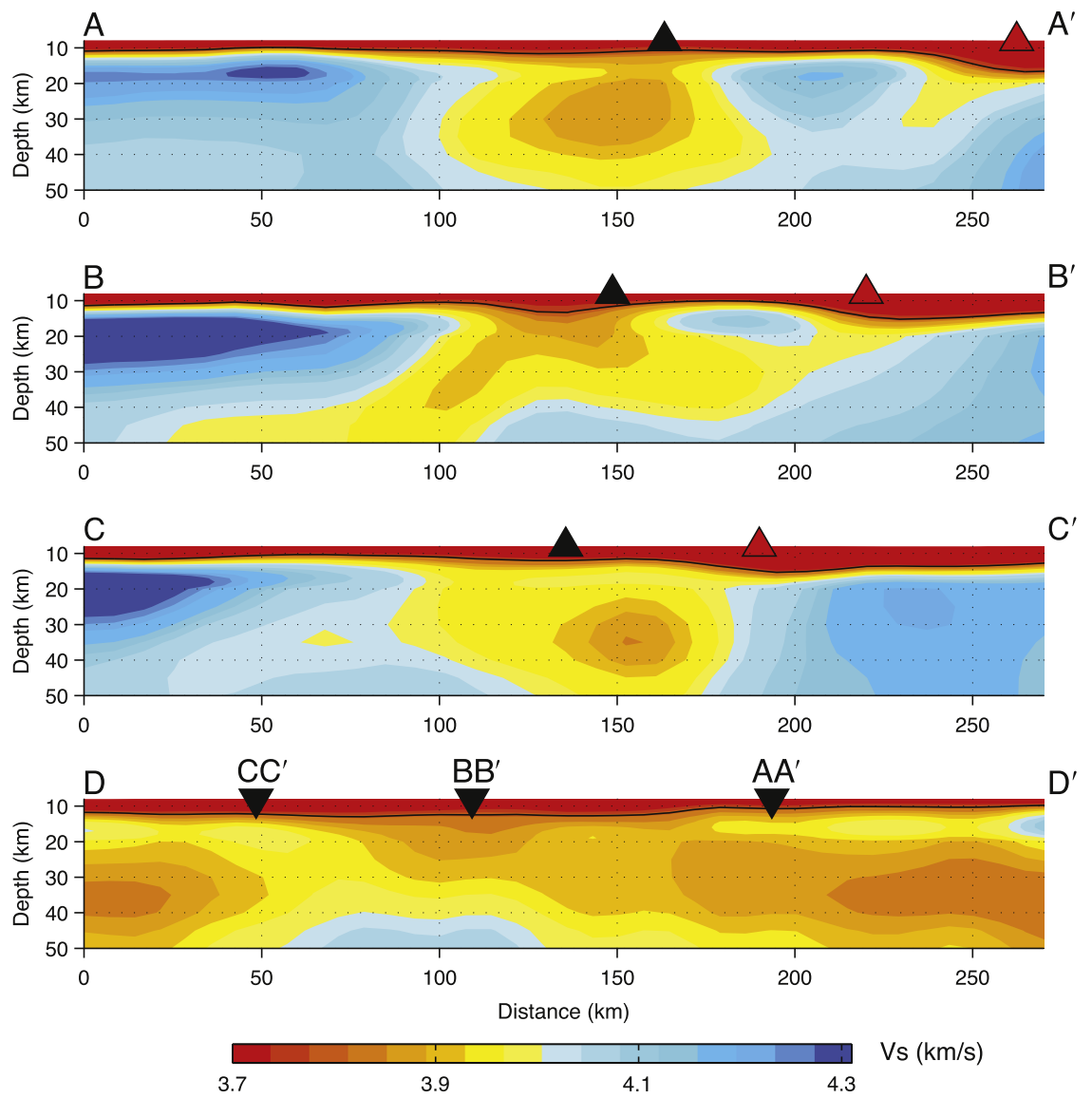

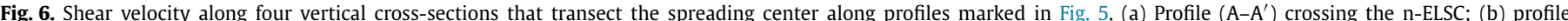

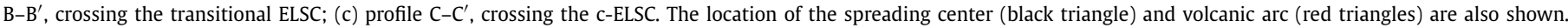

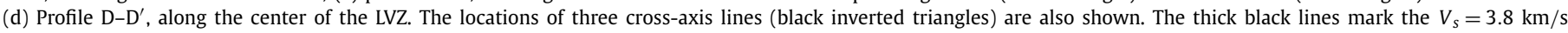
contour as a proxy for the Moho. (For interpretation of the references to color in this figure legend, the reader is referred to the web version of this article.)

in Arai and Dunn, 2014). A velocity discontinuity is permitted at the Moho. Fig. S6 shows that even with a thinner crust, the inverted average shear velocity at n-ELSC is still higher than that at c-ELSC by $\sim 0.3 \mathrm{~km} / \mathrm{s}$ (75\% of the original difference). Note that final crustal velocities are sensitive to the starting crustal model and thus we do not interpret fine scale structure within the crust. Velocities below $15 \mathrm{~km}$ are relatively unaffected by the choice of crustal models.

Previous analysis of active-source seismic data revealed a narrow ( $<8 \mathrm{~km}$ wide), semi-continuous low velocity zone in the crust beneath the ELSC (Dunn et al., 2013). Such narrow features are beyond the resolution of our imaging due to the long wavelengths $(>20 \mathrm{~km})$ of the surface waves used.

\subsubsection{Uppermost mantle low velocity zone (LVZ)}

Beginning at $10 \mathrm{~km}$ depth below the seafloor a continuous low velocity zone (LVZ), defined as regions with shear velocity anomaly $<-1 \%$, is imaged beneath the ELSC (Fig. 5b-f). The shape and amplitude of the LVZ varies along the ELSC, as does its depth. In the top $10-20 \mathrm{~km}$ of the mantle, the LVZ has a relatively uniform width along the ELSC, and is asymmetric with respect to the ridge in the north. At the southernmost part of the c-ELSC, the slowest velocity in the LVZ is centered beneath the ridge. The center of the LVZ progressively shifts to the west toward the n-ELSC and lies beneath the ILSC at the northern terminus of ELSC. The width of the LVZ at $10 \mathrm{~km}$ depth is about $30 \mathrm{~km}$, similar to that imaged beneath the EPR (Toomey et al., 2007). The LVZ appears continuous across three overlapping spreading centers (OSCs) between four ELSC segments, consistent with observations of a continu- ous mantle velocity anomaly at the EPR $9^{\circ} \mathrm{N}$ (Dunn et al., 2001; Toomey et al., 2007). However, separate narrow LVZs as observed in the crust (Dunn et al., 2013) would probably not be detectable due to the small offset of these OSCs $(1.5-8 \mathrm{~km})$ and the limited horizontal resolution.

Below $30 \mathrm{~km}$ depth the width of the LVZ increases to more than $100 \mathrm{~km}$. The LVZ exhibits greater along-ridge variations at depth, with the slowest velocity imaged beneath the northern part of the basin between the n-ELSC and CLSC. This observation is consistent with results from a previous 2D seismic survey across the CLSC, which showed that the region of slowest velocities lies between the CLSC and the Tonga Ridge (Conder and Wiens, 2006). A vertical velocity profile through the center of the LVZ illustrates the significant along-ridge variation of the LVZ (Fig. 6, profile D-D'). The LVZ beneath the northern segments of the ELSC appears to have lower shear velocity than the southern segments (by $\sim 0.1 \mathrm{~km} / \mathrm{s}$ ).

\subsubsection{Relationship between $L V Z$ and sub-arc anomaly}

A sub-arc low velocity zone (SLZ), with less velocity contrast than the LVZ, is imaged below the extremely slow arc crust at Tonga Ridge (Fig. 5c-d and Fig. 6). The SLZ dips westward below $20 \mathrm{~km}$ depth instead of extending vertically beneath the arc. Vertical smearing of the thick low velocity arc crust may result in a low velocity artifact in the uppermost mantle, partly contributing to the SLZ. However the deeper part of the SLZ $(>25 \mathrm{~km})$ does not lie beneath any significant crustal thickness anomaly and thus cannot be directly attributed to a crustal artifact. Fig. 6 illustrates the spatial relationship between the LVZ and SLZ along three ridge perpendicular lines. Across the central ELSC (Fig. 6, profile $C-C^{\prime}$ ), 

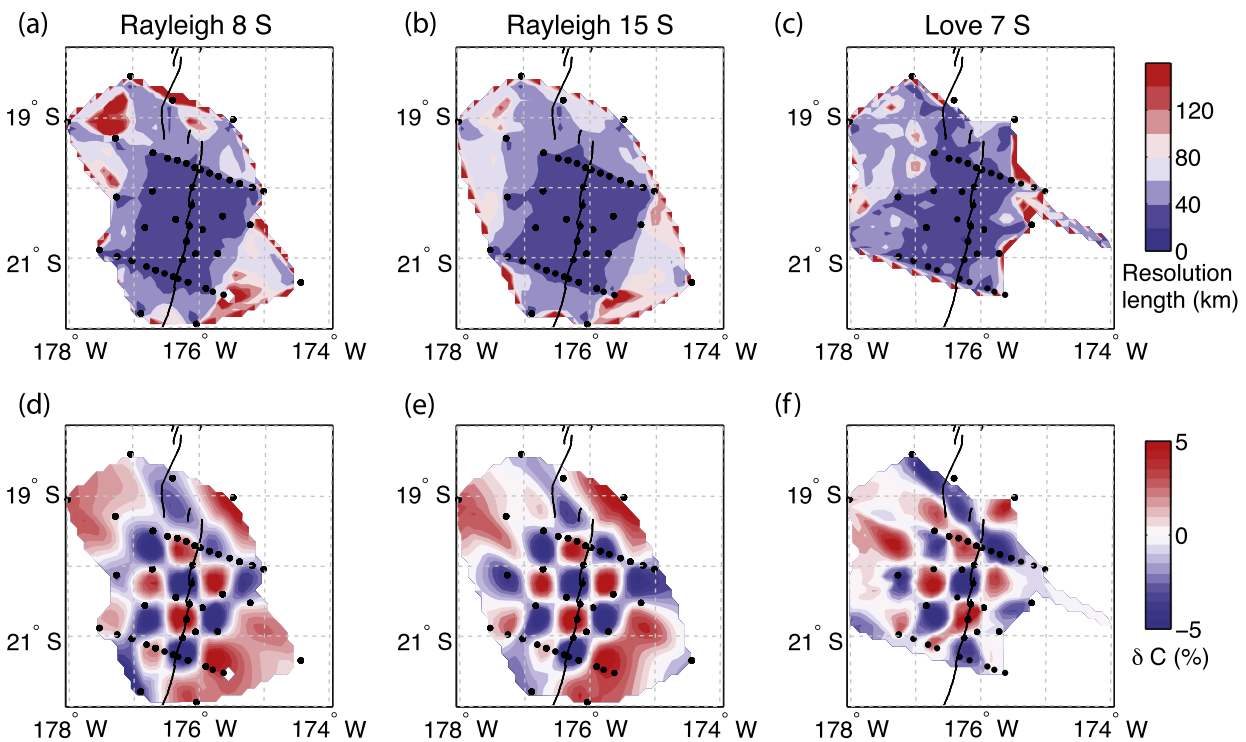

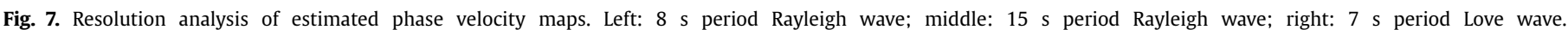

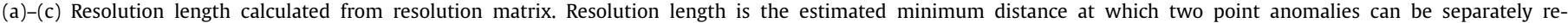

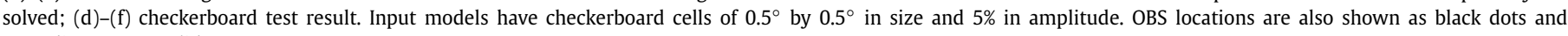
spreading center solid curves.

where the ridge is about $50 \mathrm{~km}$ from the volcanic arc, the LVZ and SLZ are merged together and the slowest velocity lies between the ridge and arc. Resolution analysis (Appendix A) shows that the horizontal resolution length in this area is less than $40 \mathrm{~km}$ (Fig. 7). Therefore we are confident that this feature is not caused by the horizontal smearing of two separate slow anomalies. Across the transitional ELSC (profile B-B'), the LVZ and SLZ become separated near the surface, but remain connected at greater depth. At the northern ELSC $\left(A-A^{\prime}\right)$ where the ridge is farther away from the volcanic arc $(\sim 90 \mathrm{~km})$, the LVZ and SLZ are distinct both near the surface and at depth. The slowest velocities in the LVZ in this transect lies beneath the northern ELSC, while the SLZ appears disconnected from the LVZ.

\subsubsection{Possible effect of attenuation}

We note that our seismic velocity model is obtained at surface wave periods (6-18 s) and has not been corrected for the dispersion effects due to attenuation. The physical dispersion effect is potentially important for areas where attenuation is high and where melting is expected (Goes et al., 2012; Kanamori and Anderson, 1977; Tian et al., 2013). However the attenuation structure beneath the ELSC is unknown thus hindering the accurate physical dispersion correction of the 3D model. A previous tomographic study by Roth et al. (1999) revealed a wide upper mantle high attenuation zone beneath the adjacent CLSC with Qp as low as 90. Assuming similar values of Qp at ELSC and Qp/Qs = 1.75 (Roth et al., 1999), the correction from $10 \mathrm{~s}$ (the center of our frequency band) to $1 \mathrm{~s}$ using the absorption band model (Anderson et al., 1977) will result in up to $1.5 \%$ increase of $V_{S}$ in the LVZ. If the lateral variation of attenuation structure beneath ELSC is similar in scale as beneath the CLSC, almost the entire region of this study (with the exception of the forearc) may be underlain by high attenuation. Therefore the correction for physical dispersion will mainly introduce a constant increase of $V_{s}$ and only slightly reduce the anomaly in the LVZ.

\section{Discussion}

\subsection{Region averaged velocity structure}

Fig. 8 shows the local averaged 1D shear velocity profiles for n-ELSC, c-ELSC, Tonga Ridge and an off-axis region west of ELSC.
Tonga Ridge has the lowest shear velocities in the upper $15 \mathrm{~km}$, suggesting a thick andesitic crust with high porosity. The n-ELSC has, on average, higher crustal velocities than c-ELSC, consistent with a velocity contrast imaged by active source seismic tomography (Dunn et al., 2013). The off-axis region has crustal velocities similar to the c-ELSC, suggesting that formerly the mantle source tapped by the ridge was similar to the present day c-ELSC rather than the n-ELSC.

In the upper mantle, both the n-ELSC and c-ELSC profiles show a low velocity zone with minimum velocity of about $4.0 \mathrm{~km} / \mathrm{s}$ between $25 \mathrm{~km}$ and $40 \mathrm{~km}$ depth, presumably caused by elevated temperature and partial melt. It is not clear whether the slight velocity increase at $40-50 \mathrm{~km}$ depth denotes the bottom of the LVZ. A vertical resolution test (Appendix A) shows that the velocity anomalies deeper than $45 \mathrm{~km}$ are significantly underestimated (Fig. S7), since it's deeper than the peak of 18 s Rayleigh wave sensitivity. Wei et al. (2014), using longer period Rayleigh waves from teleseismic earthquakes, suggest a slightly deeper $(40-50 \mathrm{~km})$ and slower $(3.7 \mathrm{~km} / \mathrm{s})$ minimum velocity along the northern ELSC. The shear velocity within the low velocity zone beneath the n-ELSC is lower than that beneath the c-ELSC by $0.05 \mathrm{~km} / \mathrm{s}$, a possible result of higher temperature and melt fraction beneath the nELSC. This is consistent with the results from Wei et al. (2014), which show the LVZ becoming shallower and smaller in amplitude from north to south. The off-axis region has a high velocity lid $\left(V_{S} \approx 4.4 \mathrm{~km} / \mathrm{s}\right.$ ) at about $20 \mathrm{~km}$ depth, corresponding to the lithosphere. Below the lid, the velocity decreases to about $4.1 \mathrm{~km} / \mathrm{s}$ at $40 \mathrm{~km}$ depth, suggesting the transition from lithosphere to the asthenospheric mantle wedge. In contrast, the Tonga Ridge area is not underlain by a pronounced low velocity layer. This could be a result of thicker lithosphere, as lower temperatures are predicted beneath the Tonga Ridge (Harmon and Blackman, 2010). Thus the low velocity asthenosphere is likely below the bottom of the resolving limit ( $\sim 45 \mathrm{~km}$ depth) of this study.

\subsection{Crustal velocity contrast}

A crustal high velocity zone was imaged beneath the n-ELSC (Fig. 5), in agreement with previous active-source studies that the northern ELSC (n-ELSC) has higher crustal velocities than the central ELSC (c-ELSC) (Dunn and Martinez, 2011; Jacobs et al., 2007), 
(a)

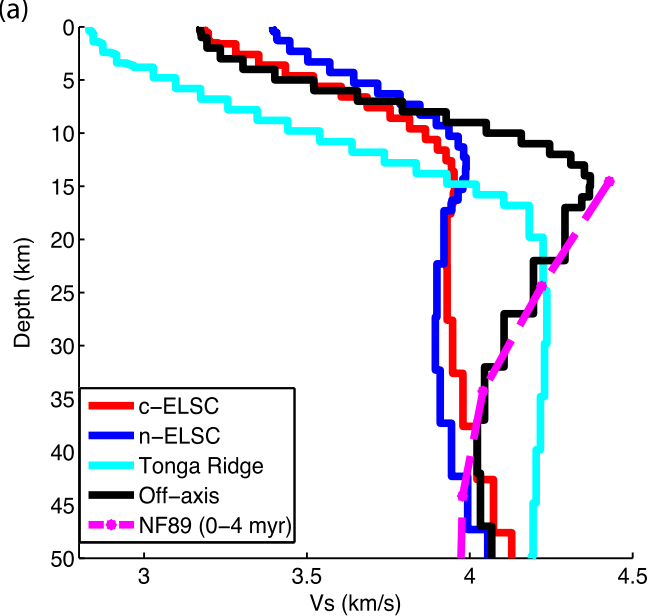

(b)

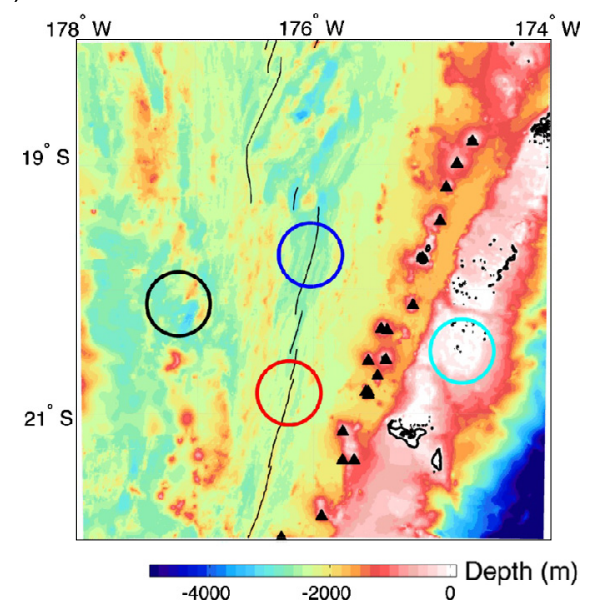

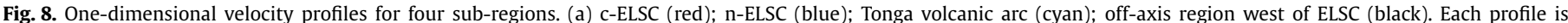

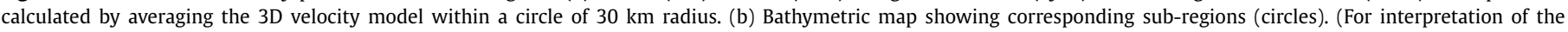
references to color in this figure legend, the reader is referred to the web version of this article.)

possibly due to lower water content in the mantle source and associated lower crustal porosity. The high velocity zone has a wedge shape, consistent with the spreading history of the ELSC. The average $V_{s}$ in the high velocity zone at $5 \mathrm{~km}$ depth is $3.7 \mathrm{~km} / \mathrm{s}$, similar to that estimated at the fast spreading EPR (Harmon et al., 2007; Yao et al., 2011), but significantly higher than the $V_{s}$ at c-ELSC $(\sim 3.5 \mathrm{~km} / \mathrm{s})$. The boundary of the high velocity zone is abrupt rather than gradual, corresponding to the sudden deepening of the seafloor and change in seafloor morphology (Martinez et al., 2006). Together they are indicative of a change in crustal composition (Dunn and Martinez, 2011; Dunn et al., 2013). As previously noted, the higher velocities can be partly attributed to a thinner crust along the n-ELSC.

\subsection{Tonga Ridge and Tofua Arc}

Very slow velocities are imaged under the Tonga Ridge and Tofua Arc, corresponding to highly porous volcanic crust. The shear velocity increases from 3.8 to $4.2 \mathrm{~km} / \mathrm{s}$ between $15-20 \mathrm{~km}$ depth, indicative of the Moho discontinuity occurring within this interval (Fig. 8). This is consistent with a previous bound on the minimum crustal thickness (Crawford et al., 2003) and estimates of 20-25 km from older data (Mitronovas and Isacks, 1971; Raitt et al., 1955). In the top $10 \mathrm{~km}$ the slowest velocities are imaged beneath the Tonga Ridge, suggesting thick volcanic sediments. At $15-20 \mathrm{~km}$ depth, the slowest velocities are beneath the active Tofua Arc volcanoes, likely indicative of seismically slow andesitic crust. A sub-arc low velocity zone (SLZ) is imaged beneath the arc crust between 20 and $40 \mathrm{~km}$ (Fig. 6). This anomaly may extend to larger depths, since the lower extent of the anomaly may not be well resolved. The SLZ trends westwards into the mantle wedge rather than extending vertically beneath the arc, similar to anomalies found at other volcanic arcs (Nakajima et al., 2001). The geometry of the SLZ is consistent with the thermal anomaly and hydrous melt production associated with the back-arc corner flow, as predicted by Harmon and Blackman (2010). The slow anomaly in the SLZ is indicative of high temperature and partial melt. The arc anomaly is clearly smaller in magnitude than the anomaly beneath the northern ELSC. One possible explanation is that the high ascent rate of the slab-derived hydrous melts will lead to low melt porosity (Turner et al., 2000), potentially reducing the velocity anomaly.

\subsection{Asymmetric mantle LVZ}

A laterally continuous mantle LVZ, with shear velocities as low as $3.8 \mathrm{~km} / \mathrm{s}$, is imaged beneath the ELSC, extending from $10 \mathrm{~km}$ depth down to at least $50 \mathrm{~km}$. It may represent a region of elevated temperature and partial melt beneath the ridge. The relationship between temperature, melt content and seismic velocity is dependent on water content, grain size, composition and melt geometry (Faul et al., 1994; Hammond and Humphreys, 2000; Jackson and Faul, 2010; Kelley et al., 2006; Schmeling, 1985; Takei, 2002; Wiens et al., 2008), most of which are poorly constrained in the mantle wedge. Therefore we do not attempt to provide an exact interpretation of the 3D seismic model in terms of temperature and melt content. We instead estimate the velocity anomaly that can be attributed to the effect of melt. Numerical modeling assuming 2-D mantle flow driven by plate kinematics for a transect from the trench across the ELSC predicts the maximum temperature beneath spreading axis to be $1260-1360^{\circ} \mathrm{C}$ between $10 \mathrm{~km}$ and $50 \mathrm{~km}$ depth (Harmon and Blackman, 2010). Assuming these temperatures and a olivine grain size of $1 \mathrm{~mm}$, the lowest shear velocity caused by thermal effects alone is $\sim 4.1 \mathrm{~km} / \mathrm{s}$ (calculated using the formulation of Jackson and Faul (2010), which includes both anharmonic and anelastic effects (Fig. S8). The predicted velocities also depend slightly on grain size). The inverted minimum shear velocity in the LVZ, on the other hand, ranges from $3.8 \mathrm{~km} / \mathrm{s}$ to $3.9 \mathrm{~km} / \mathrm{s}$ (6-9\% slower than the predicted velocity). Such additional velocity reduction requires the presence of melt. Although we are unable to quantify the amount of melt due to the large uncertainty in the relationship between melt and seismic velocity, the maximum melt fraction beneath ELSC is likely to occur at the top of the LVZ just below the Moho.

The variation of the LVZ along the ELSC likely indicates variation in the relative melt distribution and can provide new insights on the controlling factors of various ridge characteristics. Although the thinner crust and the absence of crustal magma lens (Jacobs et al., 2007) at the n-ELSC all suggest a limited magmatic supply, neither the width nor the amplitude of the LVZ anomaly in our results decreases significantly northward. However, the center of the LVZ progressively shifts westwards to the north, making the LVZ increasingly asymmetric relative to ELSC. A melting region with asymmetry increasing to the north has been predicted by previous numerical modeling studies as a result of the faster spreading rate and larger arc-ridge separation (Harmon and Blackman, 2010). A melt source region to the west of the n-ELSC is also supported 

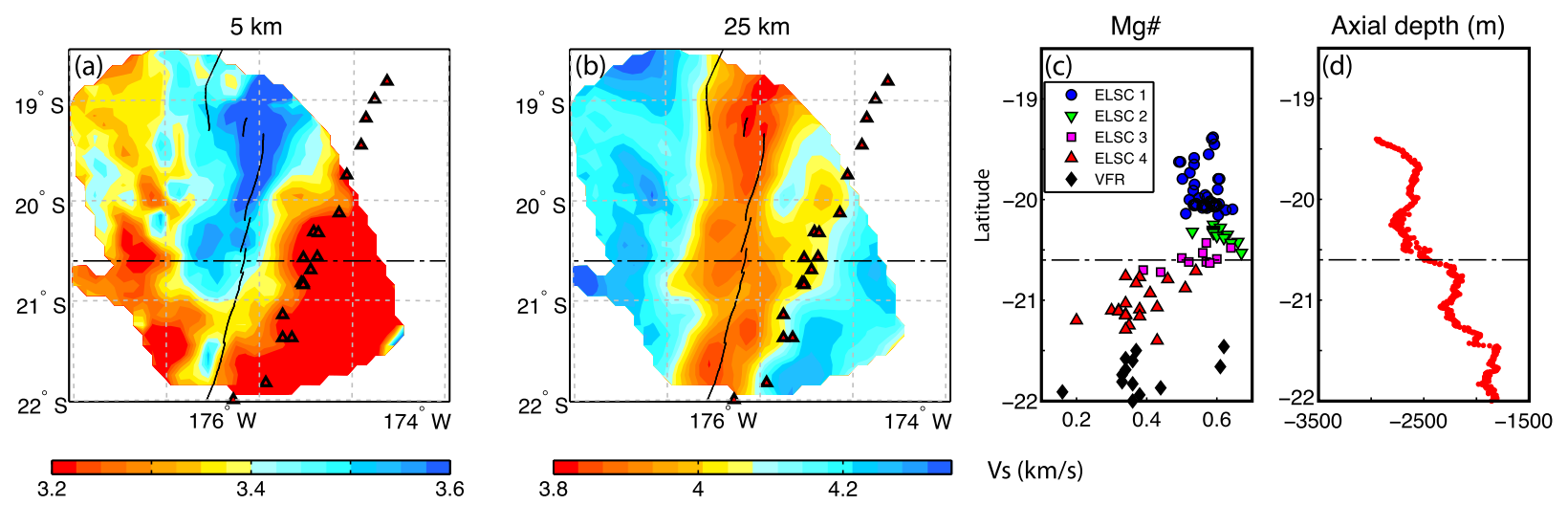

$\mathrm{Vs}(\mathrm{km} / \mathrm{s})$

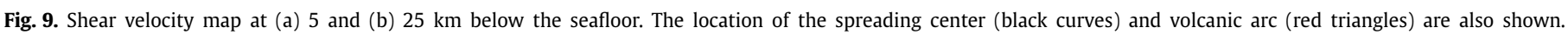

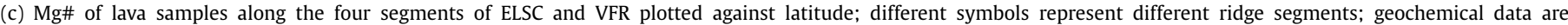

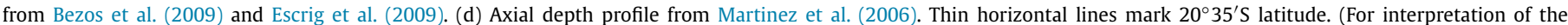
references to color in this figure legend, the reader is referred to the web version of this article.)

by asymmetric structure at depths $>50 \mathrm{~km}$ imaged by long period Rayleigh wave analysis (Wei et al., 2014). The increasing offset between the center of mantle melt production and the ridge may result in less efficient melt transport to the ridge and lead to a reduced magma supply to the n-ELSC. Similar along-ridge contrast has been observed at EPR $9^{\circ} \mathrm{N}$, where spreading segments with ridge-centered mantle melt delivery show more volcanism, while segments with off-axis mantle melt delivery have reduced volcanic activity and more extensive seafloor faulting (Fornari et al., 1998; Toomey et al., 2007; Wright et al., 1995).

\subsection{Interaction between arc and back-arc magmatic systems}

Several geophysical and geochemical observations suggest that the crust formed at the c-ELSC is distinctly different from that formed at the n-ELSC. At the c-ELSC, the crust is anomalously thick (8-9 km), has lower upper crustal velocities, and is of more felsic composition (Arai and Dunn, 2014; Dunn and Martinez, 2011; Escrig et al., 2009; Pearce et al., 1994). At the n-ELSC, the crustal thickness is within the range of normal oceanic crust $(6-7 \mathrm{~km})$, with higher upper crustal velocities and a MORB like composition (Arai and Dunn, 2014; Dunn and Martinez, 2011; Escrig et al., 2009; Pearce et al., 1994). A step-like change in mantle wedge composition, induced by the cutoff of slab-derived water as the ridge migrates away form the arc, has been proposed by previous studies (Arai and Dunn, 2014; Dunn and Martinez, 2011; Dunn et al., 2013).

Our results reveal the changing interaction of arc and back-arc magmatic systems along the ELSC. The mantle LVZ beneath the ELSC is indistinguishable from the sub-arc low velocity zone (SLZ) at the c-ELSC, gradually separates from the SLZ along the transitional ELSC, and become distinct at the n-ELSC (Fig. 6). Fig. 9 shows that the separation of the ridge and arc LVZ near $20^{\circ} 35^{\prime} \mathrm{S}$ is coincident with the sharp increase of axial depth and of $\mathrm{Mg}$ number from lava samples. This is also highly correlated with the transition in crustal velocity structure and disappearance of the melt lens along the ELSC. We suggest that the spatial separation of ridge and arc melting regions creates a change in mantle source tapped by the ELSC. At the c-ELSC and the VFR, where the center of the mantle upwelling is closer to the hydrated sub-arc mantle, the decompression melting region beneath the ridge and hydrous melting region beneath the arc are connected. Thus slab-derived water can be easily entrained by the upwelling mantle into the ridge melting region, enhancing the melt production and producing a thicker, more felsic crust (Arai and Dunn, 2014; Davies and Bickle, 1991; Kelley et al., 2006). At the n-ELSC, where the center of mantle upwelling beneath the ridge is farther away from the hydrated mantle wedge, the two melting regions are separated, at least in the upper $30 \mathrm{~km}$. Due to the mostly horizontal plate-driven mantle flow pattern, water is either transported into the sub-arc melting region or carried into the deeper mantle. As the lithosphere between the arc and back-arc thicken, slab-derived water could be further focused into the sub-arc region due to the rheological contrast at the base of the lithosphere (Wilson et al., 2014). The increasing offset between the mantle melt production zone and the ridge revealed by our seismic image may further limit the magma supply to the n-ELSC via reduced extraction efficiency. Together these mechanisms lead to the production of a thinner crust with a MORB like composition. Two-dimensional modeling work has begun to test this type of hypothesis (Cagnioncle et al., 2007; Hall, 2012; Harmon and Blackman, 2010), but 3-D flow and melt migration estimates are needed for quantitative evaluation of the laterally variable portion of the Lau mantle wedge that our seismic results have documented.

\subsection{Implication of the along-ridge variations of $L V Z$}

Although the n-ELSC appears to have reduced magmatic supply compared to the c-ELSC with thinner crust, deeper axial seafloor and less continuous crustal magma lens (Jacobs et al., 2007; Martinez et al., 2006), the upper mantle LVZ beneath the n-ELSC is wider and has lower velocities (by $\sim 0.1 \mathrm{~km} / \mathrm{s}$ ) in the $20-40 \mathrm{~km}$ depth interval (Fig. 6). Close proximity to the seismically fast lithosphere may result in faster apparent velocity in the LVZ via lateral averaging effects, especially at c-ELSC where spreading is slower and lithosphere is thicker. However, this is unlikely a dominant effect because the lithosphere adjacent to the LVZ is generally less than $20 \mathrm{~km}$ thick (as predicted by previous 2D modeling work of Conder et al., 2002; Harmon and Blackman, 2010), while the imaged north-south variation in LVZ is most prominent below $30 \mathrm{~km}$. Moreover, our resolution analysis (Appendix A) suggests that features separated by $>50 \mathrm{~km}$ are well resolved (Fig. 7). Therefore we conclude that the along-ridge variation in LVZ velocity and width is not due to a lateral averaging effect, but reflects actual change in physical properties of the upper mantle along the ELSC.

The lower shear velocity beneath the n-ELSC may be caused by higher temperature and/or higher melt fraction in the LVZ. Mantle temperatures beneath the spreading center are predicted by $2-\mathrm{D}$, kinematically driven flow models to be $5-10^{\circ} \mathrm{C}$ higher beneath the n-ELSC than the south end of c-ELSC (Harmon and Blackman, 2010), due to higher spreading rate and more vigorous upwelling. However, to account for the observed velocity difference of $0.1 \mathrm{~km} / \mathrm{s}$ a temperature difference of $>100 \mathrm{~K}$ is needed 
(Jackson and Faul, 2010), an order of magnitude larger than the predicted difference. We therefore suggest that temperature difference alone cannot explain the observed velocity gradient.

An alternative explanation is that the lower shear velocity beneath the n-ELSC reflects higher melt content compared to the c-ELSC. Although the n-ELSC exhibits reduced magmatic activity compared to the c-ELSC and is regarded as having lower melt production rate due to less slab-derived water, the increased offset between mantle LVZ and the ridge at the n-ELSC, as imaged in this study, could reduce the efficiency of melt extraction. Therefore it is possible that only part of the melt being generated is transported to the ridge, while the rest remains in the mantle. On the other hand, Wei et al. (2014) suggest that while high water content enhances melt production at c-ELSC/VFR, it also facilitates melt transport, either as a result of lower melt viscosity (Giordano et al., 2008) or larger grain size (Karato, 1989). As a result, melt beneath the c-ELSC is extracted more efficiently, leading to less melt remaining in the mantle. Therefore the variation in LVZ velocity along ELSC may reflect mainly the melt extraction efficiency rather than melt production rate along the ELSC.

\section{Conclusion}

The 3D seismic images obtained in this study have important implications for the factors controlling the geological, geophysical and geochemical characteristics of the Eastern Lau Spreading Center. As the distance from ridge to the arc increases, the arc and ridge melting region changes from connected to separated in the uppermost mantle, likely the result of changes in the mantle wedge flow pattern. This spatial separation may lead to the cutoff of hydrated mantle source material for the ridge, reducing melt production and changing the chemical composition of the melt. The new velocity model provides supporting evidence for the previously proposed mechanism that the abrupt changes in lava composition and ridge morphology along ELSC are governed by the changing interaction between arc and back-arc magmatic systems. This is the first mantle imaging confirmation of a direct connection between crustal and uppermost mantle processes.

Our model also reveals an unexpected increase in offset between the ridge and the center of mantle melt supply northward along the ELSC, which could reduce melt extraction efficiency beneath the ridge. The combination of a lower melt production rate and lower extraction rate may result in a reduced-melt n-ELSC, leading to the flat faulted ridge morphology, thinner crust and disappearance of the melt lens. Lower melt extraction rate may also lead to higher melt content in the mantle, as suggested by the larger width and amplitude of seismic anomaly beneath nELSC. Taken together, our results suggest that the changing mantle wedge flow pattern along strike, a result of changing plate geometry, likely poses the ultimate control on the ridge characters at the ELSC.

\section{Acknowledgement}

We thank the scientific party, captain, crew, and technical teams of R/V Kilo Moana and R/V Roger Revelle for their work that made this study possible. The ocean bottom seismographs deployed are part of the instrument pool supported and maintained by OBSIP. We thank the OBS teams at Lamont-Doherty Earth Observatory and Woods Hole Oceanographic Institution, in particular Andrew Barclay, David Gassier, Ted Koczynski Vincent Oletu, Timothy Kane, Daniel Kot, Kenneth Peal and Peter Lemmond for their help in deploying and recovering the instruments as well as providing sensor information. Y. Zha thanks Göran Ekström, Roger Buck and Ge Jin for their helpful discussions and two anonymous reviewers for their careful reviews that improved this manuscript. This work was supported by National Science Foundation grants OCE04-26369, OCE04-30463, OCE04-26428, and OCE04-26408.

\section{Appendix A. Resolutions and uncertainties}

\section{A.1. Phase velocity uncertainties}

The uncertainties of the phase velocity maps are estimated using a bootstrap algorithm (Calkins et al., 2011; Menke and Menke, 2012). We randomly resample the selected dispersion curves and invert for a series of bootstrap phase velocity maps. The final uncertainties are obtained by statistical analysis of 500 such maps and are used in the shear velocity inversion process.

Uncertainties in the phase velocity are typically less than $0.05 \mathrm{~km} / \mathrm{s}$ for Rayleigh waves and less than $0.1 \mathrm{~km} / \mathrm{s}$ for Love waves (Fig. S2 and Fig. S3). Uncertainties are smallest at the interior of the array and increase towards its edge, reflecting the poorer ray coverage away from the array center. Average uncertainty also increases with period, because fewer inter-station dispersion measurements are available at longer periods. Love wave uncertainties are largest near Tonga Ridge, where ray coverage is sparse and extremely slow phase velocities $(-15 \%)$ are imaged. The estimated uncertainties are used to weight phase velocity maps at different period in the shear velocity inversion.

\section{A.2. Horizontal resolution}

Understanding the horizontal resolution of our ambient noise tomography is essential for distinguishing well-resolved anomalies from inversion artifacts. We use the method of (Barmin et al., 2001) to estimate the resolution length for $7 \mathrm{~s}$ Love wave as well as 8 and $15 \mathrm{~s}$ Rayleigh waves (Fig. 7, a-c). Resolution length can be interpreted as the minimum distance at which two spike-like anomalies can be separately resolved (Barmin et al., 2001). The resolution lengths for both Love and Rayleigh waves range from 20 to $60 \mathrm{~km}$ for most of the model. Along the ELSC between the two linear lines of OBS, ray coverage is the densest and resolution length is generally $<40 \mathrm{~km}$. Resolution is lower near the CLSC and the eastern Tonga Ridge, where resolution lengths range from 60 to $100 \mathrm{~km}$. Therefore, near ELSC features with scales larger than $50 \mathrm{~km}$ are considered well resolved, while outside of this central region only features $100 \mathrm{~km}$ in scale are interpreted. We also conducted a standard checkerboard test to demonstrate the varying spatial resolution, using an input model with checkerboard anomalies of $0.5^{\circ} \times{ }^{*} 0.5^{\circ}$ in size and $5 \%$ in amplitude (Fig. 7, d-f). The anomaly patterns are well resolved near the center of the array, with sharp velocity boundaries preserved.

\section{A.3. Vertical resolution}

We perform a series of synthetic tests to evaluate the vertical resolution of the shear velocity inversion. We generate synthetic models by inserting low velocity layers (LVL) into a 2-layer starting model at different depths. The starting model has a 7-km-thick crust $\left(V_{S}=3.5 \mathrm{~km} / \mathrm{s}\right)$ and a mantle half-space $\left(V_{S}=4.2 \mathrm{~km} / \mathrm{s}\right)$. The thickness of the LVL increases with depth, from $4 \mathrm{~km}$ to $20 \mathrm{~km}$ (Fig. S7). Random noise between $\pm 0.03 \mathrm{~km} / \mathrm{s}$ is added to the synthetic dispersion curve before inversion is performed, following the practices of Calkins et al. (2011). The inversion parameters used in the synthetic test are the same as those used for the 3D inversion.

Our results suggest that an LVL less than $5 \mathrm{~km}$ thick cannot be resolved even in the crust due to the lack of high frequency data in the inversion. Instead, the inversion smooths out any LVL in the input model and yields a lower velocity throughout the crust. Therefore we do not interpret any fine scale $(<5 \mathrm{~km})$ structure within the crust. The introduction of a crustal LVL also creates a 
low velocity artifact in the upper mantle. This artifact decreases in amplitude with depth, and becomes negligible at depths over $10 \mathrm{~km}$ beneath the Moho. A LVL thicker than $10 \mathrm{~km}$ in the upper mantle is resolvable. The depths of lowest velocity generally correspond to the center of the LVL in the input models, but intrinsic vertical smearing spreads the LVL to about twice its original thickness, and reduces its magnitude to roughly $40 \%-70 \%$ of that in the input model. Consequently, the amplitudes of recovered velocity anomalies are underestimated and thus represent the lower limit of the actual anomaly. Near the bottom of the model $(\sim 50 \mathrm{~km}$ depth), the resolution is limited by the longest ambient noise period used in the inversion (18 s). Although the recovered peak of the anomaly is still inside the LVL, the anomaly tends to be asymmetric, with smaller amplitude in the lower part of the LVL. Therefore we believe that slow anomalies deeper than $45 \mathrm{~km}$ are significantly underestimated.

\section{Appendix B. Supplementary material}

Supplementary material related to this article can be found online at http://dx.doi.org/10.1016/j.epsl.2014.10.019.

\section{References}

Aki, K., 1957. Space and time spectra of stationary stochastic waves, with special reference to microtremors. Bull. Earthq. Res. Inst. Univ. Tokyo 35, 415-456.

Anderson, D.L., Kanamori, H., Hart, R.S., Liu, H.P., 1977. Earth as a seismic absorptionband. Science 196 (4294), 1104-1106. http://dx.doi.org/10.1126/Science.196. 4294.1104.

Arai, R., Dunn, R.A., 2014. Seismological study of Lau back arc crust: mantle water, magmatic differentiation, and a compositionally zoned basin. Earth Planet. Sci. Lett. 390, 304-317. http://dx.doi.org/10.1016/j.epsl.2014.01.014.

Barmin, M.P., Ritzwoller, M.H., Levshin, A.L., 2001. A fast and reliable method for surface wave tomography. Pure Appl. Geophys. 158 (8), 1351-1375. http:// dx.doi.org/10.1007/Pl00001225.

Bensen, G.D., Ritzwoller, M.H., Barmin, M.P., Levshin, A.L., Lin, F., Moschetti, M.P., Shapiro, N.M., Yang, Y., 2007. Processing seismic ambient noise data to obtain reliable broad-band surface wave dispersion measurements. Geophys. J. Int. 169 (3), 1239-1260. http://dx.doi.org/10.1111/j.1365-246X.2007.03374.x.

Bezos, A., Escrig, S., Langmuir, C.H., Michael, P.J., Asimow, P.D., 2009. Origins of chemical diversity of back-arc basin basalts: a segment-scale study of the Eastern Lau Spreading Center. J. Geophys. Res., Solid Earth 114. http://dx.doi.org/ 10.1029/2008jb005924. Art. no. B06212.

Cagnioncle, A.M., Parmentier, E.M., Elkins-Tanton, L.T., 2007. Effect of solid flow above a subducting slab on water distribution and melting at convergent plate boundaries. J. Geophys. Res., Solid Earth 112. http://dx.doi.org/10.1029/ 2007jb004934. Art. no. B09402.

Calkins, J.A., Abers, G.A., Ekstrom, G., Creager, K.C., Rondenay, S., 2011. Shallow structure of the Cascadia subduction zone beneath western Washington from spectral ambient noise correlation. J. Geophys. Res., Solid Earth 116. http://dx. doi.org/10.1029/2010jb007657.

Conder, J.A., Wiens, D.A., 2006. Seismic structure beneath the Tonga arc and Lau back-arc basin determined from joint Vp, Vp/Vs tomography. Geochem. Geophys. Geosyst. 7. http://dx.doi.org/10.1029/2005gc001113. Art. no. Q03018.

Conder, J.A., Wiens, D.A., Morris, J., 2002. On the decompression melting structure at volcanic arcs and back-arc spreading centers. Geophys. Res. Lett. 29 (15) http://dx.doi.org/10.1029/2002gl015390. Art. no. 1727.

Crawford, W.C., Webb, S.C., 2000. Identifying and removing tilt noise from lowfrequency $(<0.1 \mathrm{~Hz})$ seafloor vertical seismic data. Bull. Seismol. Soc. Am. 90 (4), 952-963. http://dx.doi.org/10.1785/0119990121.

Crawford, W.C., Wiens, D.A., Dorman, L.M., Webb, S.C., Wiens, D.A., 2003. Tonga Ridge and Lau Basin crustal structure from seismic refraction data. J. Geophys. Res., Solid Earth 108 (B4). http://dx.doi.org/10.1029/2001jb001435.

Davies, J.H., Bickle, M.J., 1991. A physical model for the volume and composition of melt produced by hydrous fluxing above subduction zones. Philos. Trans. R. Soc., Math. Phys. Eng. Sci. 335 (1638), 355-364. http://dx.doi.org/10.1098/rsta. 1991.0051.

Dunn, R.A., Forsyth, D.W., 2007. 1.12 - Crust and lithospheric structure - seismic structure of mid-ocean ridges. In: Schubert, G. (Ed.), Treatise on Geophysics. Elsevier, Amsterdam, pp. 419-443.

Dunn, R.A., Martinez, F., 2011. Contrasting crustal production and rapid mantle transitions beneath back-arc ridges. Nature 469 (7329), 198-202. http://dx.doi.org/ 10.1038/nature09690.

Dunn, R.A., Martinez, F., Conder, J.A., 2013. Crustal construction and magma chamber properties along the Eastern Lau Spreading Center. Earth Planet. Sci. Lett. 371, 112-124. http://dx.doi.org/10.1016/J.Epsl.2013.04.008.
Dunn, R.A., Toomey, D.R., Detrick, R.S., Wilcock, W.S., 2001. Continuous mantle melt supply beneath an overlapping spreading center on the East Pacific Rise. Science 291 (5510), 1955-1958. http://dx.doi.org/10.1126/science.1057683.

Ekström, G., Abers, G.A., Webb, S.C., 2009. Determination of surface-wave phase velocities across USArray from noise and Aki's spectral formulation. Geophys. Res. Lett. 36 (18). http://dx.doi.org/10.1029/2009gl039131.

Escrig, S., Bezos, A., Goldstein, S.L., Langmuir, C.H., Michael, P.J., 2009. Mantle source variations beneath the Eastern Lau Spreading Center and the nature of subduction components in the Lau basin-Tonga arc system. Geochem. Geophys. Geosyst. 10. http://dx.doi.org/10.1029/2008gc002281. Art. no. Q04014.

Faul, U.H., Toomey, D.R., Waff, H.S., 1994. Intergranular basaltic melt is distributed in thin, elongated inclusions. Geophys. Res. Lett. 21 (1), 29-32.

Fornari, D.J., Haymon, R.M., Perfit, M.R., Gregg, T.K.P., Edwards, M.H., 1998. Axial summit trough of the east Pacific rise $9^{\circ}-10^{\circ} \mathrm{N}$ : geological characteristics and evolution of the axial zone on fast spreading mid-ocean ridges. J. Geophys. Res., Solid Earth 103 (B5), 9827-9855.

Giordano, D., Russell, J.K., Dingwell, D.B., 2008. Viscosity of magmatic liquids: a model. Earth Planet. Sci. Lett. 271 (1-4), 123-124. http://dx.doi.org/10.1016/ j.epsl.2008.03.038

Goes, S., Armitage, J., Harmon, N., Smith, H., Huismans, R., 2012. Low seismic velocities below mid-ocean ridges: attenuation versus melt retention. J. Geophys. Res., Solid Earth 117. http://dx.doi.org/10.1029/2012jb009637. Art. no. B12403.

Hall, P.S., 2012. On the thermal evolution of the mantle wedge at subduction zones. Phys. Earth Planet. Inter. 198, 9-27. http://dx.doi.org/10.1016/J.Pepi.2012.03.004.

Hammond, W.C., Humphreys, E.D., 2000. Upper mantle seismic wave velocity: effects of realistic partial melt geometries. J. Geophys. Res. 105 (B5), 10975-10986. http://dx.doi.org/10.1029/2000JB900041.

Harmon, N., Blackman, D.K., 2010. Effects of plate boundary geometry and kinematics on mantle melting beneath the back-arc spreading centers along the Lau Basin. Earth Planet. Sci. Lett. 298 (3-4), 334-346. http://dx.doi.org/10.1016/ J.Epsl.2010.08.004.

Harmon, N., Forsyth, D., Webb, S., 2007. Using ambient seismic noise to determine short-period phase velocities and shallow shear velocities in young oceanic lithosphere. Bull. Seismol. Soc. Am. 97 (6), 2009-2023. http://dx.doi.org/ $10.1785 / 0120070050$.

Hawkins, J.W., Lonsdale, P.F., Macdougall, J.D., Volpe, A.M., 1990. Petrology of the axial ridge of the Mariana trough backarc spreading center. Earth Planet. Sci. Lett. 100 (1-3), 226-250. http://dx.doi.org/10.1016/0012-821x(90)90187-3.

Herrmann, R.B., Ammon, C.J. (Eds.), 2004. Surface Waves, Receiver Functions and Crustal Structure. Saint Louis University, St. Louis.

Jackson, I., Faul, U.H., 2010. Grainsize-sensitive viscoelastic relaxation in olivine: towards a robust laboratory-based model for seismological application. Phys. Earth Planet. Inter. 183 (1-2), 151-163. http://dx.doi.org/10.1016/J.Pepi.2010.09.005.

Jacobs, A.M., Harding, A.J., Kent, G.M., 2007. Axial crustal structure of the Lau backarc basin from velocity modeling of multichannel seismic data. Earth Planet. Sci. Lett. 259 (3-4), 239-255. http://dx.doi.org/10.1016/J.Epsl.2007.04.021.

Kanamori, H., Anderson, D.L., 1977. Importance of physical dispersion in surfacewave and free oscillation problems - review. Rev. Geophys. 15 (1), 105-112. http://dx.doi.org/10.1029/Rg015i001p00105.

Karato, S., 1989. Grain growth kinetics in olivine aggregates. Tectonophysics 168 (4), 255-273.

Karig, D.E., 1970. Ridges and basins of Tonga-Kermadec Island arc system. J. Geophys. Res. 75 (2), 239. http://dx.doi.org/10.1029/Jb075i002p00239.

Kato, T., Beavan, J., Matsushima, T., Kotake, Y., Camacho, J.T., Nakao, S., 2003. Geodetic evidence of back-arc spreading in the Mariana trough. Geophys. Res. Lett. 30 (12). http://dx.doi.org/10.1029/2002gl016757. Art. no. 1625

Kelley, K.A., Plank, T., Grove, T.L., Stolper, E.M., Newman, S., Hauri, E., 2006. Mantle melting as a function of water content beneath back-arc basins. J. Geophys. Res. Solid Earth 111. http://dx.doi.org/10.1029/2005jb003732. Art. no. B09208.

Lin, F.-C., Moschetti, M.P., Ritzwoller, M.H., 2008. Surface wave tomography of the western United States from ambient seismic noise: Rayleigh and Love wave phase velocity maps. Geophys. J. Int. 173 (1), 281-298. http://dx.doi.org/ 10.1111/j.1365-246X.2008.03720.X.

Martinez, F., Fryer, P., Becker, N., 2000. Geophysical characteristics of the southern Mariana Trough, $11^{\circ} 50^{\prime} \mathrm{N}-13^{\circ} 40^{\prime} \mathrm{N}$. J. Geophys. Res., Solid Earth 105 (B7), 16591-16607. http://dx.doi.org/10.1029/2000jb900117.

Martinez, F., Taylor, B., Baker, E.T., Resing, J.A., Walker, S.L., 2006. Opposing trends in crustal thickness and spreading rate along the back-arc Eastern Lau Spreading Center: implications for controls on ridge morphology, faulting, and hydrothermal activity. Earth Planet. Sci. Lett. 245 (3-4), 655-672. http:// dx.doi.org/10.1016/J.Epsl.2006.03.049.

Menke, W., 2012. Geophysical Data Analysis: Discrete Inverse Theory, 3rd edition, pp. $1-293$

Menke, W., Menke, J.E., 2012. Environmental Data Analysis with MatLab. Elsevier, Amsterdam, Boston.

Menke, W., Zha, Y., Webb, S., Blackman, D.K., 2014. Seismic anisotropy indicates ridge-parallel asthenospheric flow beneath the Eastern Lau Spreading Center. Submitted for publication.

Mitronovas, W., Isacks, B.L., 1971. Seismic velocity anomalies in the upper mantle beneath the Tonga-Kermadec Island Arc. J. Geophys. Res. 76 (29), 7154-7180. 
Nakajima, J., Matsuzawa, T., Hasegawa, A., Zhao, D., 2001. Three-dimensional structure of $\mathrm{Vp}$, Vs, and $\mathrm{Vp} / \mathrm{Vs}$ beneath northeastern Japan: implications for arc magmatism and fluids. J. Geophys. Res., Solid Earth 106 (B10), 21843-21857. http://dx.doi.org/10.1029/2000jb000008.

Nishimura, C.E., Forsyth, D.W., 1989. The anisotropic structure of the upper mantle in the pacific. Geophys. J. Int. 96 (2), 203-229. http://dx.doi.org/10.1111/ J.1365-246x.1989.Tb04446.X.

Pearce, J.A., Ernewein, M., Bloomer, S.H., Parson, L.M., Murton, B.J., Johnson, L.E., 1994. Geochemistry of Lau Basin volcanic rocks: influence of ridge segmentation and arc proximity. Geol. Soc. (Lond.) Spec. Publ. 81 (1), 53-75. http:// dx.doi.org/10.1144/gsl.sp.1994.081.01.04.

Pearce, R.B., 1995. The geochemistry of Llandovery and Wenlock age K-bentonites in the southern uplands. Scott. J. Geol. 31, 23-28.

Peate, D.W., Kokfelt, T.F., Hawkesworth, C.J., Van Calsteren, P.W., Hergt, J.M., Pearce, J.A., 2001. U-series isotope data on Lau Basin glasses: the role of subductionrelated fluids during melt generation in back-arc basins. J. Petrol. 42 (8), 1449-1470. http://dx.doi.org/10.1093/Petrology/42.8.1449.

Pelletier, B., Lagabrielle, Y., Benoit, M., Cabioch, G., Calmant, S., Garel, E., Guivel, C., 2001. Newly identified segments of the Pacific-Australia plate boundary along the North Fiji transform zone. Earth Planet. Sci. Lett. 193 (3-4), 347-358. http://dx.doi.org/10.1016/S0012-821x(01)00522-2.

Raitt, R.W., Fisher, R.L., Mason, R.G., 1955. Tonga trench. Spec. Pap., Geol. Soc. Am. 62, 237-254.

Roth, E.G., Wiens, D.A., Dorman, L.M., Hildebrand, J., Webb, S.C., 1999. Seismic attenuation tomography of the Tonga-Fiji region using phase pair methods. J. Geophys. Res., Solid Earth 104 (B3), 4795-4809. http://dx.doi.org/10.1029/ 1998jb900052.

Roux, P., 2005. P-waves from cross-correlation of seismic noise. Geophys. Res. Lett. 32 (19). http://dx.doi.org/10.1029/2005gl023803.

Schmeling, H., 1985. Numerical-models on the influence of partial melt on elastic, anelastic and electric properties of rocks. 1. Elasticity and anelasticity. Phys. Earth Planet. Inter. 41 (1), 34-57.

Shapiro, N.M., Campillo, M., 2004. Emergence of broadband Rayleigh waves from correlations of the ambient seismic noise. Geophys. Res. Lett. 31 (7). http://dx.doi.org/10.1029/2004gl019491.

Shapiro, N.M., Campillo, M., Stehly, L., Ritzwoller, M.H., 2005. High-resolution surface-wave tomography from ambient seismic noise. Science 307 (5715), 1615-1618. http://dx.doi.org/10.1126/Science.1108339.

Sinton, J.M., Fryer, P., 1987. Mariana trough lavas from $18^{\circ} \mathrm{N}$ - implications for the origin of back arc basin basalts. J. Geophys. Res., Solid Earth 92 (B12), 12782-12802. http://dx.doi.org/10.1029/Jb092ib12p12782.

Sleeper, J.D., Martinez, F., 2014. Controls on segmentation and morphology along the back-arc Eastern Lau Spreading Center and Valu Fa Ridge. J. Geophys. Res., Solid Earth 119 (3), 1678-1700. http://dx.doi.org/10.1002/2013jb010545.

Smith, M.L., Dahlen, F.A., 1973. Azimuthal dependence of Love and Rayleigh-wave propagation in a slightly anisotropic medium. J. Geophys. Res. 78 (17), 3321-3333. http://dx.doi.org/10.1029/Jb078i017p03321.

Snieder, R., 2004. Extracting the Green's function from the correlation of coda waves: a derivation based on stationary phase. Phys. Rev. E 69 (4). http://dx.doi. org/10.1103/PhysRevE.69.046610.

Spudich, P., Orcutt, J., 1980. A new look at the seismic velocity structure of the oceanic-crust. Rev. Geophys. 18 (3), 627-645. http://dx.doi.org/10.1029/ Rg018i003p00627.

Takei, Y., 2002. Effect of pore geometry on V-P/V-S: from equilibrium geometry to crack. J. Geophys. Res. 107 (B2). http://dx.doi.org/10.1029/2001jb000522.

Takeo, A., Nishida, K., Isse, T., Kawakatsu, H., Shiobara, H., Sugioka, H., Kanazawa, T. 2013. Radially anisotropic structure beneath the Shikoku Basin from broadband surface wave analysis of ocean bottom seismometer records. J. Geophys. Res. Solid Earth 118 (6), 2878-2892. http://dx.doi.org/10.1002/jgrb.50219.

Taylor, B., Martinez, F., 2003. Back-arc basin basalt systematics. Earth Planet. Sci. Lett. 210 (3-4), 481-497. http://dx.doi.org/10.1016/S0012-821x(03)00167-5.

Taylor, B., Zellmer, K., Martinez, F., Goodliffe, A., 1996. Sea-floor spreading in the Lau back-arc basin. Earth Planet. Sci. Lett. 144 (1-2), 35-40. http://dx.doi.org/ 10.1016/0012-821x(96)00148-3.

Tian, Y., Shen, W.S., Ritzwoller, M.H., 2013. Crustal and uppermost mantle shear velocity structure adjacent to the Juan de Fuca Ridge from ambient seismic noise. Geochem. Geophys. Geosyst. 14 (8), 3221-3233. http://dx.doi.org/10.1002/ Ggge.20206.

Toomey, D.R., Jousselin, D., Dunn, R.A., Wilcock, W.S.D., Detrick, R., 2007. Skew of mantle upwelling beneath the East Pacific Rise governs segmentation. Nature 446 (7134), 409-414. http://dx.doi.org/10.1038/nature05679.

Turner, S., Bourdon, B., Hawkesworth, C., Evans, P., 2000. Ra-226-Th-230 evidence for multiple dehydration events, rapid melt ascent and the time scales of differentiation beneath the Tonga-Kermadec island arc. Earth Planet. Sci. Lett. 179 (3-4), 581-593. http://dx.doi.org/10.1016/S0012-821x(00)00141-2.

Turner, I.M., Peirce, C., Sinha, M.C., 1999. Seismic imaging of the axial region of the Valu Fa Ridge, Lau Basin - the accretionary processes of an intermediate back-arc spreading ridge. Geophys. J. Int. 138 (2), 495-519. http://dx.doi.org/ 10.1046/J.1365-246x.1999.00883.X

Vallier, T.L., et al., 1991. Subalkaline andesite from Valu Fa Ridge, a back-arc spreading center in southern Lau Basin: petrogenesis, comparative chemistry, and tectonic implications. Chem. Geol. 91 (3), 227-256. http://dx.doi.org/10.1016/ 0009-2541(91)90002-9.

Wei, S.S., Wiens, D.A., Zha, Y., Webb, S., Blackman, D.K., Dunn, R.A., Conder, J.A submitted for publication. Seismic tomography indicates melt transport beneath the Lau back-arc basin.

Wiens, D.A., Conder, J.A., Faul, U.H., 2008. The seismic structure and dynamics of the mantle wedge. Annu. Rev. Earth Planet. Sci. 36, 421-455.

Wiens, D.A., Seama, N., Conder, J.A., 2006. Mantle structure and flow patterns beneath active back-arc basins inferred from passive seismic and electromagnetic methods. Geophys. Monogr. 166, 43-62.

Wilson, C.R., Spiegelman, M., van Keken, P.E., Hacker, B.R., 2014. Fluid flow in subduction zones: the role of solid rheology and compaction pressure. Earth Planet Sci. Lett. 401, 261-274. http://dx.doi.org/10.1016/j.epsl.2014.05.052.

Wright, D.J., Haymon, R.M., Fornari, D.J., 1995. Crustal fissuring and its relationship to magmatic and hydrothermal processes on the East Pacific Rise crest $\left(9^{\circ}-12^{\prime}\right.$ to $\left.54^{\prime} \mathrm{N}\right)$. J. Geophys. Res., Solid Earth 100 (B4), 6097-6120. http://dx.doi.org/10.1029/94jb02876.

Yao, H., Gouédard, P., Collins, J.A., McGuire, J.J., van der Hilst, R.D., 2011. Structure of young East Pacific Rise lithosphere from ambient noise correlation analysis of fundamental- and higher-mode Scholte-Rayleigh waves. C. R. Géosci. 343 (8-9), 571-583. http://dx.doi.org/10.1016/j.crte.2011.04.004.

Yoshizawa, K., Kennett, B.L.N., 2002. Determination of the influence zone for surface wave paths. Geophys. J. Int. 149 (2), 440-453. http://dx.doi.org/10.1046 J.1365-246x.2002.01659.X

Zellmer, K.E., Taylor, B., 2001. A three-plate kinematic model for Lau Basin opening. Geochem. Geophys. Geosyst. 2.

Zha, Y., Webb, S.C., Menke, W., 2013. Determining the orientations of ocean bottom seismometers using ambient noise correlation. Geophys. Res. Lett. 40 (14) 3585-3590. http://dx.doi.org/10.1002/Grl.50698.

Zhao, D.P., Xu, Y.B., Wiens, D.A., Dorman, L., Hildebrand, J., Webb, S., 1997. Depth extent of the Lau back-arc spreading center and its relation to subduction processes. Science 278 (5336), 254-257. http://dx.doi.org/10.1126/ Science.278.5336.254 